\title{
Projected changes in tropical cyclone climatology and landfall in the Southwest \\ Indian Ocean region under enhanced anthropogenic forcing
}

Published in Climate Dynamics:

Malherbe J, Engelbrecht FA and Landman W (2013) Projected changes in tropical cyclone climatology and landfall in the South west Indian $O$ cean region under enhancedanthropogenic forcing. Cimate Dynamics 40: 2867 2886

Johan Malherbe

Agricultural Research Council, South Africa

Depantm ent of Geography, Geoinform atics and Meteorology, University of Pretoria, Pretoria, South Africa

$+27824147006$

$+27123231157$

$\underline{\text { Johan@ arcagric.za }}$

F.A. Engelbrecht

CSIR Natural Resources and the Environment: Clim ate Studies, Modelling and Environmental Health, Pretoria, South Africa

W.A. Landman

CSIR Natural Resources and the Environment: Clim ate Studies, Modelling and Environmental Health, Pretoria, South Africa

Depantm ent of Geography, Geoinform atics and Meteorology, University of Pretoria, Pretoria, South Africa 


\section{Abstract}

The conformal-cubic atmospheric model (CCAM), a variable-resolution global model, is applied at high spatial resolution to perform simulations of present-day and future dimate over southern Africa and over the Southwest Indian Ocean. The model is forced with the bias-corrected seasurface temperatures and sea-ice of six coupled global climate models (CGCMs) that contributed to Assessment Report 4 (AR4) of the Intergovernmental Panel on Climate Change (IPCC). All six simulations are for the period 1961-2100, under the A2 emission scenario. Projections for the latter part of the $21^{\text {st }}$ century indicate a decrease in the occurrence of tropical cyclones over the Southwest Indian Ocean adjacent to southern Africa, as well as a northward shift in the preferred landfall position of these systems over the southern African subcontinent. A concurrent increase in January to March rainfall is projected for northern Mozambique and southern Tanzania, with decreases projected further south over semi-arid areas such as the Limpopo River Basin where these systems make an important contribution as main cause of widespread heavy rainfall. It is shown that the projected changes occur in relation to larger scale atmospheric temperature, pressure and wind profiles of thesouthern African region and adjacent oceans.

\section{Key words}

Tropical cyclone; Indian Ocean; southern Africa; climate change; landfall; atm ospheric model

\section{Introduction}

Tropical cyclones of the Southwest Indian Ocean (SWIO) basin make landfall over Madagascar and/or Mozambique about three times per year (Mavume et al. 2009). Apart from the devastation caused by storm surges over coastal regions during landfall, rainfall associated with tropical cyclones can also cause widespread flooding over the eastern parts of the southern African interior including the Limpopo River Basin (Reason and Keibal 2004; Crimp and Mason 1999), a semi-arid region including parts of Mozambique, Zimbabwe, South Africa and Botswana. Tropical cyclones and less intense tropical lows originating from the SWIO are in fact responsible for a large portion of the widespread heavy rainfall events that occur over the eastern parts of southern Africa. Between 1948 and 2008, a total of 45 such systems caused rainfall over the Limpopo River Basin, after making landfall over the southern African subcontinent (Malherbe et al. 2012). Assessment Report Four (AR4) of the IPCC points out that only a small number of studies have to date explored the potential impact of enhanced 
anthropogenic forcing on the attributes of tropical cyclones over the SW IO (Christensen et al. 2007).

Changes in the frequency, tracks and intensity of tropical cyclones over various parts of the globe during the recorded past have been inferred by the study of historical cyclone track data bases and/or datasets of synoptic-scale circulation systems (Nicholls et al. 1998; Klotzbach 2006; Elsner et al. 2008; Mavume et al. 2009). The projections of climate models have additionally been used to gain insight into the potential impact of enhanced anthropogenic forcing on tropical cyclones (e.g Camargo et al. 2007a; Royer et al. 1998; Sugi et al. 2002; W alsh et al. 2004). The analysis of the future attributes of tropical systems, as projected by atmospheric global circulation models (ACCMs) or by coupled global circulation models (CGCMs), has been performed either by the tracking of simulated tropical cyclone-like vortices (TCLVs) or by inferring whether the simulated large scale conditions favor tropical cyclone formation and intensity, using indices based on atmospheric and surface variables.

Tracking algorithms of TCLVs follow anomalies in several atmospheric variables associated with tropical cyclones, in time and space. Certain threshold values are used to define the intensity of the system, and to distinguish TCLVs from coldcore lows. The position of the TCLV is determined by the geopotential height anomaly in the lower levels of the atmosphere (Walsh and Watterson 1997) or the sea-level pressure anomaly (Bengtsson et al. 1995; T sutsui 2002; Sugi et al. 2002) and/or sea-level pressure gradient (Tsutsui 2002) or relative vorticity anomaly (eg. Bengtsson et al. 2007a). The height/pressure anomaly in some algorithms needs to be detected in the vicinity of a vorticity anomaly at the lower levels (Bengtsson et al. 1995; Walsh and Watterson 1997; Camargo and Zebiak 2002; Sugi et al. 2002). Wind speed at the lower levels is sometimes used to ascertain the intensity of the system and needs to exceed a minimum value for the identification of a TCLV (Bengtsson et al. 1995; Nguyen and Walsh 2001; Sugi et al. 2002). Criteria used to identify a system as warm-cored include lower tropospheric wind speed exceeding that in the upper troposphere (Bengtsson et al. 1995; Nguyen and Walsh 2001; Sugi et al. 2002) and/or that the average temperature in the troposphere (at 850, 700, 500 and $300 \mathrm{hPa}$ ) in the vicinity of the system needs to be higher than in the surrounding area (Nguyen and Walsh 2001; Sugi et al. 2002) 
- as also reflected in the thickness of the 700 to $200 \mathrm{hPa}$ level (Tsustui 2002). Finally, the duration of the TCLV also needs to exceed a certain time limit in order to be noted (Bengtsson et al. 1995; Sugi et al. 2002). After identification of a TCLV, several criteria are sometimes relaxed. Threshold values for certain variables are also adjusted according to the resolution of simulated data ( $\mathrm{W}$ alsh et al. 2007; Sugi et al. 2009; Camargo and Zebiak 2002) and ocean basin (Camargo and Zebiak 2002). For example, for low-level wind speed, threshold values can range between 11 and $17 \mathrm{~m} / \mathrm{s}$, depending on the spatial resolution of the data (Bengtsson et al. 1995; Walsh et al. 2004; Walsh et al. 2007; Sugi et al. 2009).

CGCMs have been used to study the influence of enhanced anthropogenic forcing on tropical cyclones (e.g. Bengtsson et al. 1995; Tsutsui 2002; Bengtsson et al. 2006) even when applied at spatial resolutions too coarse to represent realistically the intensity of tropical cyclone vortices, hence necessitating the relaxation of certain criteria for the identification of TCLVs (e.g. Bengtsson et al. 1995; Camargo and Zebiak 2002, Sugi et al. 2009). High resolution atmospheric global circulation models (ACCMs) and nested or nudged regional climate models (RCMs) have also been used to obtain more detailed projections of the effects of enhanced anthropogenic forcing on tropical cyclone attributes (Walsh and Katzfey 2000; Nguyen and Walsh 2001; Walsh et al. 2004; Sugi et al. 2009; Murakami and Wang 2010). The skill demonstrated by ACCMs of various resolutions in simulating the present day tropical cyclone climatology has however been reported to be low over the Southern Indian Ocean (SIO), with an equator ward displacement of tropical cyclone tracks over the region (Camargo et al. 2005; Sugi et al. 2009). The topography of the island of Madagascar furthermore influences the low level flow and hence the tropical vortices' evolution over the SW IO (Landman et al. 2005). This necessitates, in the case of limited-area RCMs, the inclusion of the island in the domain of the regional model. The eastern boundary should be in the region of highest simulated tropical cyclone track densities as simulated by the GCM for tropical cyclones moving into the Mozambique Channel (Landman et al. 2005). Recent years have seen the advent of variable resolution atmospheric global circulation models as an alternative to limited-area models, for the purpose of downscaling the output of CGCMs (Gibelin and Déqué 2003; Terray et al. 2004; McGregor 2005a; 2005b; Engelbrecht et al. 2009). An advantage of this approach is that the spurious 
reflection of atmospheric waves (and associated spurious vertical velocities), which may occur at the lateral boundaries of limited-area models, is avoided.

The influence of large scale environmental conditions such as vertical wind shear, steering flow and relative humidity on the occurrence of tropical cyclones (e.g. Gray 1988; Emanuel 1995; DeMaria 1996; Holland 1997) has facilitated the development of several tropical cyclone indices from seasonal averages of atmospheric and oceanic variables (e.g. Gray 1998; Bister and Emanuel 1998; Emanual and Nolen 2004; Zeng et al. 2007). Such indices have been used to gain insight into the large scale background conditions that favor tropical storm genesis (e.g. McDonald et al. 2005). Several variables thought to reflect whether the large scale environment favor tropical cyclone development are included in two widely used indices, namely The Tropical Cyclone Seasonal Genesis Parameter (TCSGP, Gray 1998) and the Tropical Cyclone Genesis Potential Index (TCGPI, Emanuel and Nolan 2004):

- The TCSGP focuses on the dynamical and thermodynamical properties of the environment. Dynamical variables include the Coriolis parameter, lowlevel absolute vorticity and tropospheric vertical wind shear, while the thermal variables include two atmospheric components namely relative humidity in the mid-troposphere and difference in equivalent potential temperature between the surface and $500 \mathrm{hPa}$ levels as well as an ocean component where thermal energy (temperature exceeding $26^{\circ}$ to a depth of $60 \mathrm{~m}$ ) is considered. A variation of this index is the Convective Tropical Cyclone Genesis Parameter (CTCGP), where the thermal component of this index is replaced by the convective potential, which is a scaled representation of the mean convective rainfall ( $\mathrm{mm} /$ day) for the relevant period (Royer et al. 1998; Caron and Jones 2008). This scale factor is estimated based on the relationship between the CGP and number of tropical cyclones formed over an area of interest. The alteration to the TCSGP index is based on the assumption that the thermal potential within the TCSGP is a representation of the potential for cumulonimbus convection, which is related to the supply of latent heat in the atmosphere (Royer et al. 1998) and which is the main energy source of tropical cyclones. 
- The TCGPI considers similar dynamic and thermal variables as used in the TCSGP and further also requires the calculation of potential intensity from vertical wind, temperature and humidity profiles. (e.g. Yu and $\mathrm{W}$ ang 2009).

The above-mentioned indices have been used successfully to investigate the influence of the El Nino Southern Oscillation (ENSO) phenomenon on tropical cyclone formation (Camargo et al. 2007b) and have also been applied to the output of the CGCMs that participated in the IPCC AR4 CMIP3, to analyze the projected change in the regional characteristics of tropical cyclones under doubling of CO2 concentrations (Caron and Jones 2008; Yu and W ang 2009; Yu et al. 2010). Several of the input atmospheric variables have also been used individually in studies towards explaining the temporal variability in the occurrence of tropical cyclones (e.g. Bell and Chelliah 2006; Bengtsson et al. 2007b; Chan and Liu 2004; Martin and Chan 2004; Sall et al. 2006; Singh et al. 2001, Vitart et al. 1999, Vimont and Kossin 2007, Zeng et al. 2007).

Large scale circulation patterns over the SWIO that have been linked to deviations in the occurrence of tropical cyclones include upper and lower tropospheric wind anomalies over the subtropics and tropics, and in particular the quasi-biennial oscillation (Jury 1993). The Madden Julian Oscillation and ENSO have also been linked to the track and frequency characteristics of tropical cyclones over the region (Liebmann et al. 1994, Vitart et al. 1999) while the landfall of tropical cyclones have been related to ENSO through an associated increase in the tropical easterlies over the SWIO during La Nina events (Vitart et al. 2003).

Anthropogenically enhanced warming could lead to a worldwide decrease in the frequency of tropical cyclones towards the end of the $21^{\text {st }}$ century (e.g. Bengtsson et al. 2007b; Yoshimura and Sugi 2005; Sugi et al. 2009). However, an increase is expected in the occurrence of the most intense systems (Bengtsson et al. 2007b; Walsh and Ryan 2000; Knutson et al. 2001; Walsh et al. 2004). Similarly ,the decrease in expected frequency of tropical cyclones under enhanced anthropogenic forcing have also been indicated for the SIO specifically (Caron and Jones 2008) as well as a slight increase in the maximum wind speed 
obtainable (Oouchi et al. 2006; Yu et al. 2010). Uncertainty in the projections is reflected to some extent in the finding of Tsusui (2002) reporting an expected increase in the number of days with tropical cyclones over the region.

In a review of trends in tropical cyclone climatology from historical datasets, Knutson et al. (2010) cites data heterogeneity (Landsea et al. 2006) and shortness of reliable data series as problematic when attempting to study the effect of anthropogenic forcing, and also to distinguish such forcing from multi-decadal climate variability (Chan 2006). Analyses of historical datasets since the early 80 s, which is the period with higher reliability of the historical record through satellite observations, have shown no statistically significant change in the global frequency of tropical cyclones and only a small change in the occurrence of category 4 and -5 hurricanes (Klotzbach 2006). Findings over the SIO include a lack of any trend in the observed number of tropical cyclones between 1960 and the late 1990s (Henderson-Sellers et al. 1998) and an upward trend in number of more intense systems since the late 1970 s or early 80 s into the $21^{\text {st }}$ century (Webster et al. 2005; Elsner et al. 2008). Utilizing a homogenous dataset starting in 1983 however, Kossin et al. (2007) found no upward trend over the basin while Kuleshov et al. (2010) suggests that the apparent upward trend in the most intense systems over the western SIO can be attributed to a change in data quality, with best track data as compiled for the region by Météo France (La Réunion) prior to 1993 deemed of insufficient reliability for trend analysis of intensity. Concerning landfall in the region of the SWIO, a decrease has been observed between 1952 and 2007 (Muvame et al. 2009). However, in an assessment of observed data from 1948 no trend has been found either in landfall occurrences over southern Africa considering all closed warm core tropical low pressure systems originating over the SWIO, or in the rainfall contributed by these systems over the Limpopo River Basin (Malherbe et al. 2012).

The present study is an evaluation of the simulated current and projected fut ure climatologies of tropical systems over the SWIO under enhanced anthropogenic forcing by a variable-resolution atmospheric model. As these systems have been shown to play an important role in significant rainfall over the eastem parts of the southern African subcontinent, specifically the Limpopo River Basin, the 
tendency of these systems to make landfall as well as their preferred area of entry and subsequent movement over the southern African subcontinent is also evaluated.

\section{Mate rials and Me thods}

The conformal-cubic atmospheric model (CCAM), a variable-resolution global model of the Commonwealth Scientific and Industrial Research Organisation (CSIRO) Marine and Atmospheric Research in Australia (McGregor 1996; 2005a; 2005b; McGregor and Dix 2001), is used to perform simulations based on the bias-corrected sea-surface temperatures (Katzfey et al. 2009) and sea-ice simulations of six coupled global climate models (CGCMs) that contributed to Assessment Report 4 (AR4) of the International Panel for Climate Change (IPCC) and the Coupled Model Intercomparison Project (CMIP3) data base. All six CGCMs responded to greenhouse gas forcing as described by the A2 (business as usual) emission scenario of the Special Report on Emission Scenarios (SRES), for the period 1961-2100.

The CGCMs are:

- GFDL-CM2.0 [The version 2.0 CGCM of the Geophysical Fluid Dynamics Laboratory (GFDL) of the National Oceanic and Atmospheric Administration (NOAA) in the United States]

- GFDL- CM2.1 [The version 2.1 CGCM of the Geophysical Fluid Dynamics Laboratory (GFDL) of the National Oceanic and Atmospheric Administration (NOAA) in the United States]

- ECHAM5/MPI-Ocean Model [The CGCM from MPI in Germany]

- UKMO-HadCM3 (The Met Office Third Hadley Centre Coupled OceanAtm osphere GCM - United Kingdom) 
- MIROC3.2-medres (Model for Interdisciplinary Research on Climate 3.2, medium resolution version, of the Japanese Agency for Marine-Earth Science and Technology)

- CSIRO Mark3.5 (The version 3.5 CGCM of the Commonwealth Scientific and Industrial Research Organisation in Australia)

These six models have been shown to simulate average sea-level pressure fields in the Southern Hemisphere and tropical belt (van Ulden and van Oldenborgh 2006), and the Madden Julian Oscillation (Sato et al. 2009) relatively well compared to the full set of CMIP3 models, whilst most members of the set of six models are also superior in simulating the response of rainfall over the Western Pacific to SST anomalies associated with ENSO (Ose and Arakawa 2009). Downscaling is performed using a multiple-nudging approach. First, CCAM is applied at quasiuniform $\mathrm{C} 48$ resolution (about $2^{\circ}$ in latitude and longitude), with forcing from the host models as specified. In a second phase of the downscaling, CCAM is subsequently integrated in stretched-grid mode over southern Africa and the SWIO, at C64 resolution (Fig. 1) and with a Schmidt factor of 2.5 (this provides a resolution of about $60 \mathrm{~km}$ over the area of interest, decreasing to about $400 \mathrm{~km}$ in the far-field). 

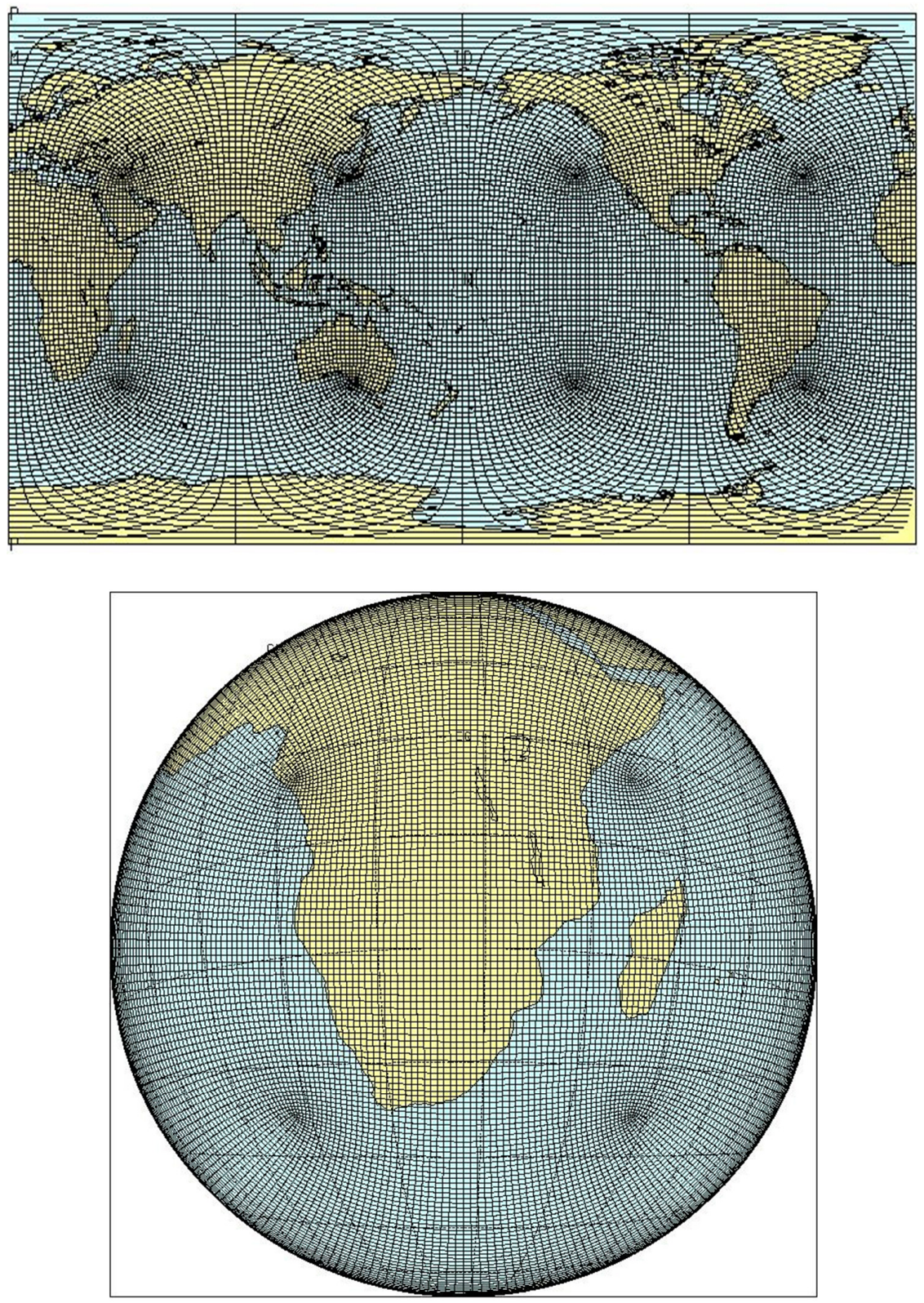

Fig. 1 Quasi-uniform C48 conformal-cubic grid (Schmidt factor 1) that provides about $200 \mathrm{~km}$ resolution in thehorizontal(top) and C64 stretched conformal-cubic grid (Schmidt factor 2.5) over southern and tropical Africa (bottom)

The high-resolution grid is chosen to optimize the resolution over the Mozambique Channel and the eastern subcontinent of southern Africa - with the purpose of resolving the influence of westward propagating tropical storms over this region with sufficient detail. The higher resolution simulations are nudged within the quasi-uniform C48 simulations, through the application of a digital 
filter (Thatcher and McGregor 2009) using a $4000 \mathrm{~km}$ length scale. The filter is applied at six-hourly intervals and from $900 \mathrm{hPa}$ upwards. Details of the experimental design, as well as a verification of the CCAM simulations of seasonal rainfall totals over southern Africa, are provided by Engelbrecht et al. (2011). Previous applications of CCAM over southern Africa have illustrated the model's ability to satisfactorily simulate not only the temperature and rainfall climatology over southern Africa (Engelbrecht 2005; Engelbrecht et al. 2009), but also the seasonal circulation and rainfall cycle (Engelbrecht et al. 2009). Recently, the model has been shown to provide realistic simulations of mid-tropospheric closed low tracks and frequency of occurrence of extreme weather events over southern Africa (Engelbrecht et al. 2012).

The 6-member CCAM-ensemble is used to study the projected changes in the characteristics of tropical systems over the SWIO and their landfall over southern Africa, through the tracking of simulated tropical-cyclone-like-vortices (TCLVs) (here defined as intense warm core closed low pressure systems of which the simulated maximum wind speed exceeds $13 \mathrm{~m} / \mathrm{s}$ ), and the larger family of warm core closed low pressure systems (of which the simulated maximum wind-speed do not necessarily exceed the $13 \mathrm{~m} / \mathrm{s}$ threshold). The $13 \mathrm{~m} / \mathrm{s}$ threshold is recommended for tracking at $200 \mathrm{~km}$ resolution (Walsh et al. 2007), equivalent to the C48 grid. With the primary focus of the study being the tracking of tropical systems from the SWIO into the eastern parts of southern Africa, the area of interest (Fig. 2) has been selected to include Madagascar and the Indian Ocean to the east of the island, to allow the tracking of tropical systems from $80^{\circ} \mathrm{E}$ westwards into southern Africa. For the purpose of model verification, the simulated 1961-1990 TCLV climatology of the CCAM-ensemble over the SW IO and southern Africa is compared to that of NCEP reanalysis data (Kalnay et al. 1996), after resampling the NCEP data to $2^{\circ}$ resolution through bicubic interpolation to obtain data with overlaying grid points. 


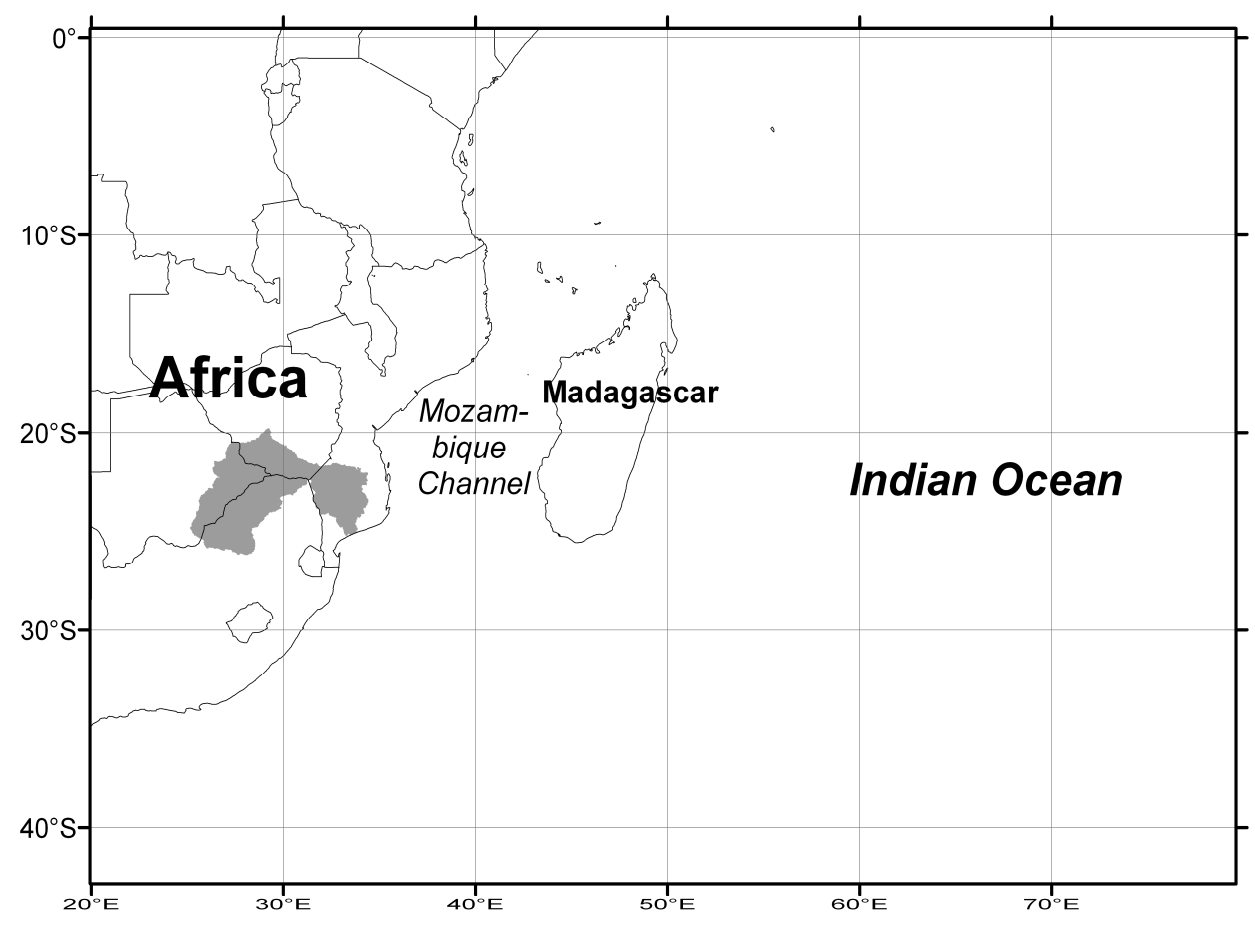

Fig. 2 Area of interest. The Limpopo River Basin is indicated

The simulation of the current and future warm-core closed low and TCLV climatologies over the region is first evaluated through the application of an objective closed low tracking algorithm (Malherbe et al. 2012; Engelbrecht et al. 2012), entailing the identification of geopotential height minima and their tracking in time. For all six ensemble members on the C48 grid, all local geopotential minima (closed lows) are identified at the $700 \mathrm{hPa}$ pressure level and tracked for every 6-hourly time-step over the entire 140-year period from 1961 to 2100. Because the majority of landfalling tropical storms over southern Africa are confined to the January-to-March period (Malherbe et al. 2012), only these months are considered in the analysis. Geopotential minima are identified by considering the geopotential height at all grid points relative to their surrounding 9-gridpoint stencil on the latitude-longitude grid. In certain cases, it is found that multiple adjacent grid points recorded the same geopotential minimum value at a given time level. For such cases, the stencil is enlarged and the algebraic average of the longitudinal and latitudinal coordinates of the grid points sharing the geopotential minimum value is taken as the position of the closed low at that time level (e.g Lambert 1988; Blender and Schubert, 2000). For each closed low identified at the $700 \mathrm{hPa}$ level, the following criteria are used to identify it as a 
warm-core low pressure system as opposed to other types of closed low pressure systems, such as cut-off lows (e.g. Taljaard 1985):

- A temperature maximum at $250 \mathrm{hPa}$ overlaying the low pressure system at $700 \mathrm{hPa}$

- A pressure minimum reflected also at $500 \mathrm{hPa}$ above the $700 \mathrm{hPa}$ low pressure minimum

- A vorticity value lower than $-0.000035 \mathrm{~s}^{-1}$ at $700 \mathrm{hPa}$ - this vorticity threshold is identified by visual inspection of several low-pressure systems at $700 \mathrm{hPa}$ from historical records and reanalysis simulations.

A further prerequisite for the identification of TCLVs from this set of closed warm core low-pressure systems is that the maximum $10 \mathrm{~m}$ wind speed surrounding the centre of the low at $700 \mathrm{hPa}$ should exceed $13 \mathrm{~m} / \mathrm{s}$ (W alsh et al. 2007)

The tracking of closed lows in time is carried out at the $700 \mathrm{hPa}$ level, after identification of a warm cored closed low in an iterative procedure where all the height minima identified at time $t$ are subjected to the tracking criteria that entail finding the closest minimum at time $t+1$ to the minimum found at time level $t$. During this procedure, consideration is given to the direction of movement of the minimum being tracked as well as the difference in the height of the minima during time step $t$ and $t+1$. This procedure has been shown to realistically track tropical systems observed over the area of interest (Malherbe et al. 2012). The number of times that the simulated tracks of warm core low-pressure systems migrate through each grid point over the area of interest as simulated by each member of the CCAM ensemble, for the 1961-1990 period as well as those found through the application of the tracking algorithm to the NCEP Reanalysis dataset are recorded. The pattern correlation between these simulated and observed values, as well as the root mean square error and standard deviation of the simulations normalised by the standard deviation of the observations (Taylor, 2001) are used as a measure of the CCAM ensemble's ability to represent the current climatology of tropical systems over the SWIO (including those moving into the subcontinent). Landfall positions are defined within the tracking algorithm by recording the latitude where a tracked low pressure system originating over the SW IO is located over a land point for the first time. 
In order to gain insight into certain projected changes simulated in preferred TCLVs and tracks in the region, the Convective Tropical Cyclone Cenesis Parameter (Royer et al. 1998) is calculated for the January to March period. The averages of each CCAM ensemble member's simulated 850 and $200 \mathrm{hPa}$ geopotential heights and wind vectors, relative humidity at $600 \mathrm{hPa}$ and simulated convective rainfall for the January-March period are used for this purpose. The scale factor used to relate the convective daily rainfall to the convective potential is 0.1379 . This value was derived from the ERA40 dataset for the approximation of the average observed number of tropical cyclones globally (Caron and Jones 2008)

\section{Re sults}

\section{Sim ulated versus observed warm core closed low pressure system and TCLV climatology}

Fig. 3 shows the ensemble average of the frequency of occurrence of TCLVs per grid point (top, shaded) for the period 1961-1990 as simulated by the CCAM, and as observed from the NCEP reanalysis data (bottom), as obtained through application of the tracking algorithm. The NCEP reanalyses data instead of Best Track data are used as a comparison in order to evaluate the CCAM ensemble output to data of similar resolution. The individual TCLV tracks, from which the frequency of occurrence per grid point is calculated, is also shown for the observed tracks (bottom) and one for one of the CCAM ensemble members (top). 

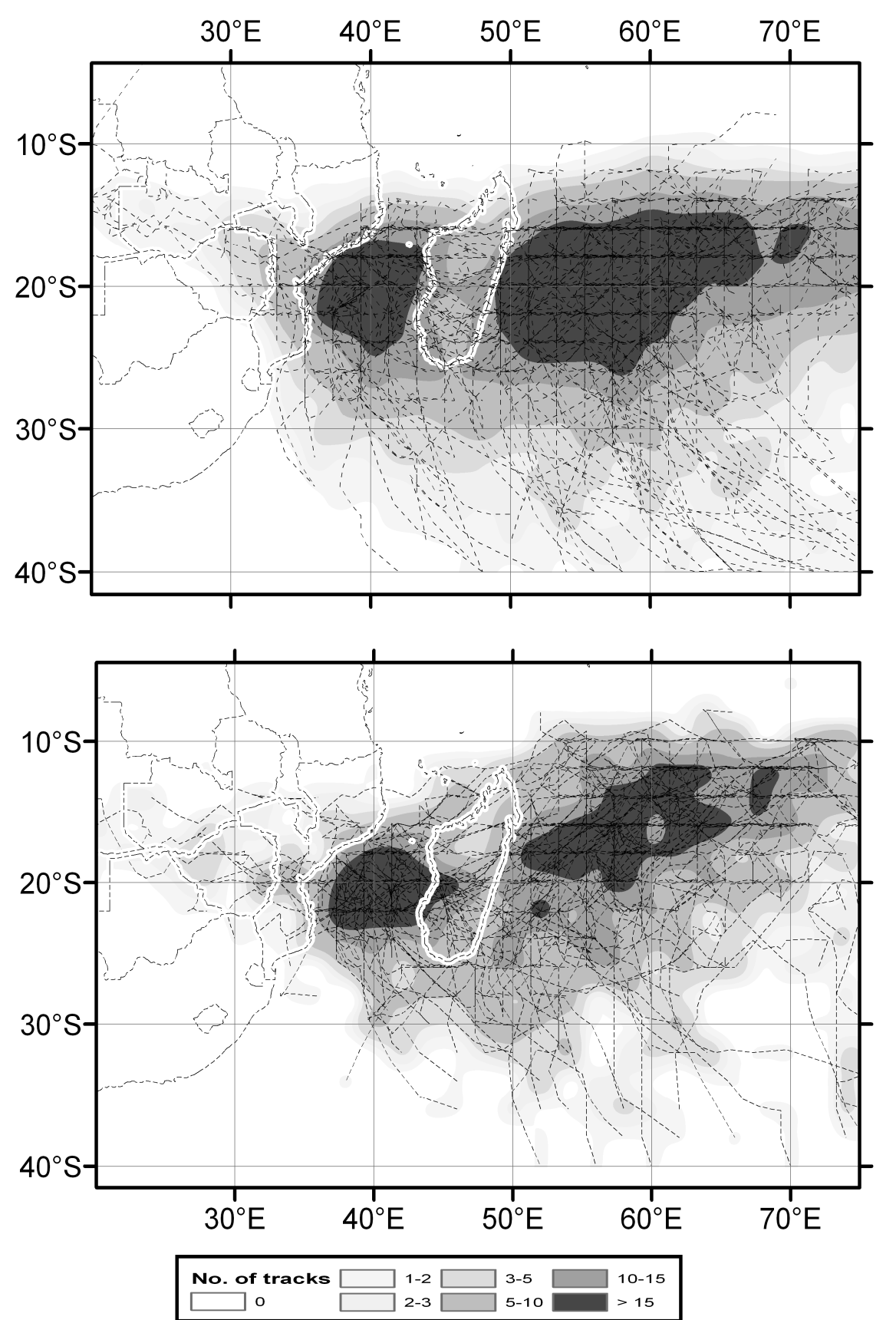

Fig. 3 Frequency of occurrence of TCLVs per grid point, as calculated from the ensemble average of the CCAM tracks (top, shaded) and as observed from the NCEP reanalysis data tracks (bottom shaded). The actual simulated tracks for the CCAM-ECHAM5 ensemble menber is indicated (top), and similarly for the reanalysis data (bottom). Units are number of occurrences per grid point over the January to March period 
Fig. 4 shows the track frequency per $2^{\circ}$ grid point for the period 1961-1990 based on information from the International Best Track Archive for Climate Stewardship (IBTrACS - Knapp et al. 2010) over the SWIO for the JanuaryMarch period. Information regarding tracks in the SWIO within this repository is provided by Regional Specialized Meteorological Center La Réunion.

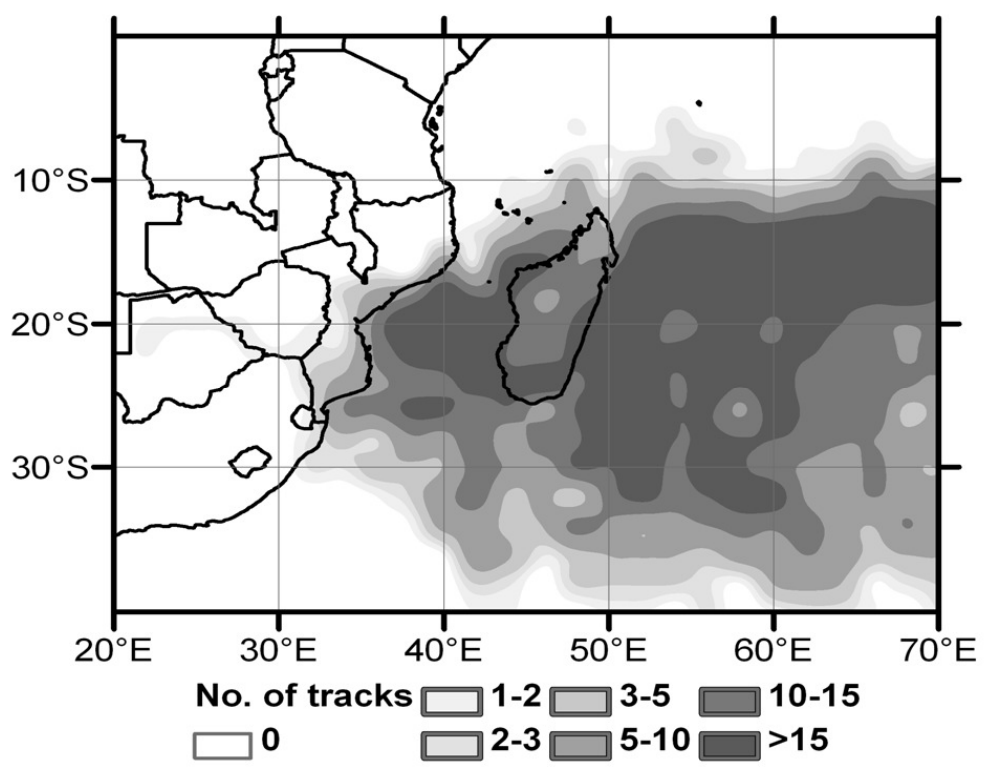

Fig. 4 Frequency of occurrence of tropical cyclones per $2^{\circ}$ grid point based on information from the IBTrACS for the 1961-1990 period. Units are number of occurrences per grid point over the January to March period

The track frequency displayed in Fig. 4, based on the IBTrACS data set, represents the tracks of all named storms over the SW IO during the 1961-1990 period. For lack of intensity information for all storms (e.g. Mavume et al. 2009), all named storms are considered irrespective of intensity information. For this reason, and an underestimation of tropical cyclone intensity in reanalysis datasets (Schenkel and Hart, 2012), the track frequency in Fig 4 represents a larger number of systems than that tracked from the NCEP reanalysis dataset (Fig. 3). It serves however as an indication that the preferred tracks of systems as determined from the tracking algorithm applied to the NCEP data is realistic. The highest concentration of TCLVs over the SWIO, the movement of systems around the northern edge of Madagascar and their southeastward and southward movement 
out of the SWIO region, their landfall tendency and westward and northwestward propagation of some of the systems into the subcontinent as simulated by the CCAM ensemble, are also observed in the NCEP reanalysis dataset over the period 1961-1990 (Fig. 3). These characteristics are captured in the simulations of the individual CCAM ensemble members, as shown in Figs.5a and b. 


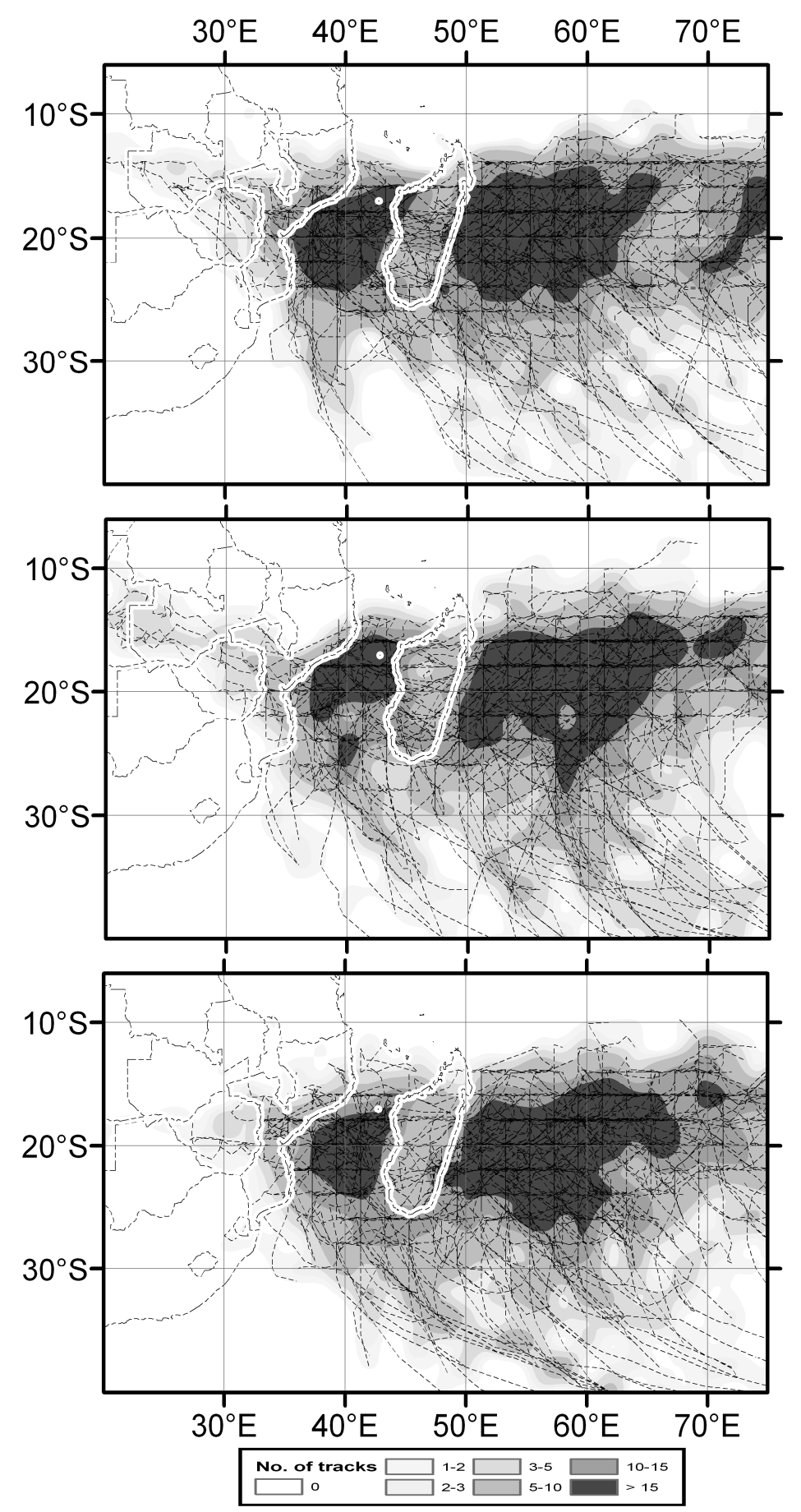

Fig. 5a Frequency of occurrence of TCLVs (shaded) per grid point for the period 1961-1990 as simulated by CCAM-CSIROMk3.5 (top), CCAM-ECHAM5 (middle), CCAM-UKHADcm3 (bottom). The actual tracks simulated by each CCAM ensemble nember are also indicated 


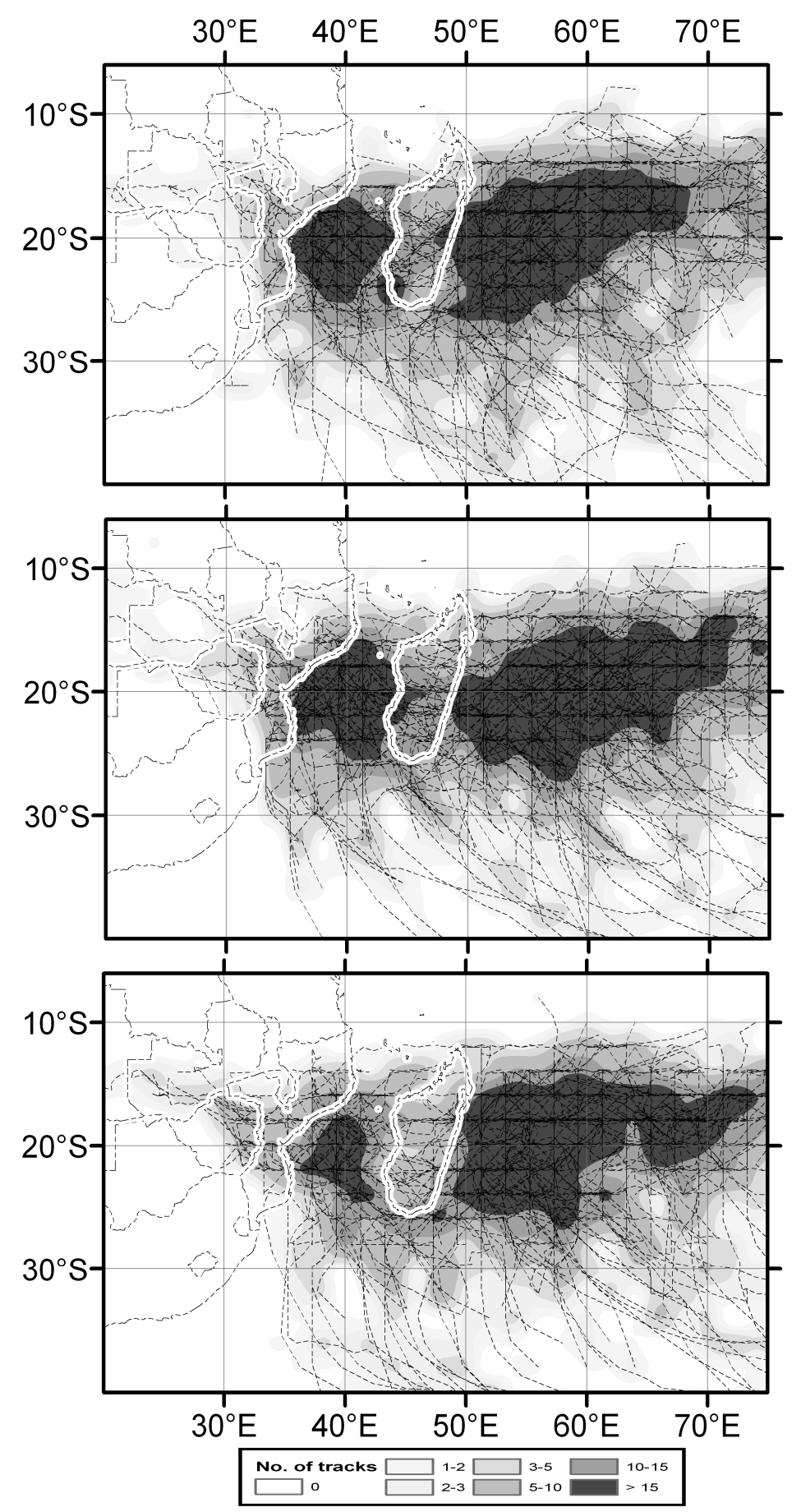

Fig. 5b Frequency of occurrence of TCLVs (shaded) per grid point for the period 1961-1990 as simulated by CCAM-MIROC (top), CCAM-GFDLcm2.0 (middle) and CCAM-GFDLcm2.1 (bottom). The actual tracks simulated by each CCAM ensemble member are also indicated

The CCAM ensemble members display a high degree of agreement in the simulation of the current distribution of TCLVs over the SWIO, with the 
ensemble mean showing superior correspondence to observations compared to individual ensemble members, as quantified by the Taylor Diagram (Fig 6). However, the standard deviation of the simulated storms is higher than the standard deviation of the reanalysis.

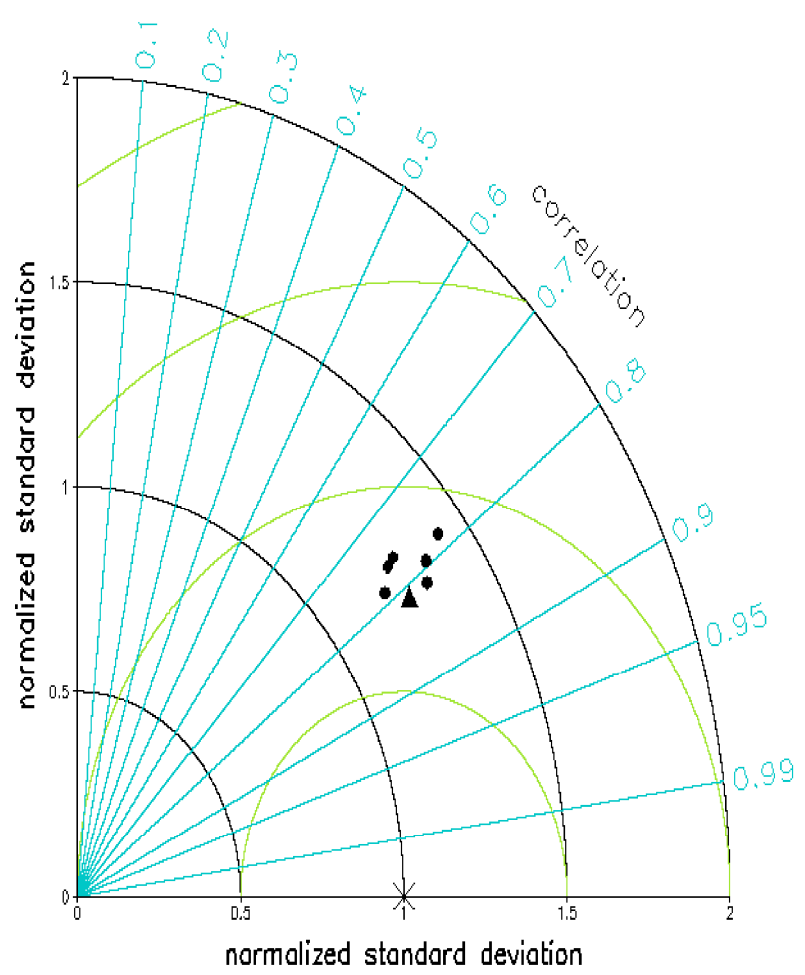

Fig. 6 Taylor diagram showing the statistical comparison of thesimulation of TCLs frequency of occurrence per grid point of the individual CCAM ensemble members (circles) and the CCAM ensemble mean (triangle) over the SWIO with the reanalysis distribution (cross)

The pattern correlation of the individual members range between 0.76 and 0.82 , with the ensemble mean having the highest pattern correlation with the observed field. Furthermore, the ensemble mean has the smallest normalised root mean square error when compared to the observed field (owing to the smooth nature of the ensemble field relative to the individual members), and second lowest difference in the normalised standard deviation. Overall, the main attributes of the tracks of landfalling warm core closed lows are captured realistically by the ensemble mean (Fig. 7). 

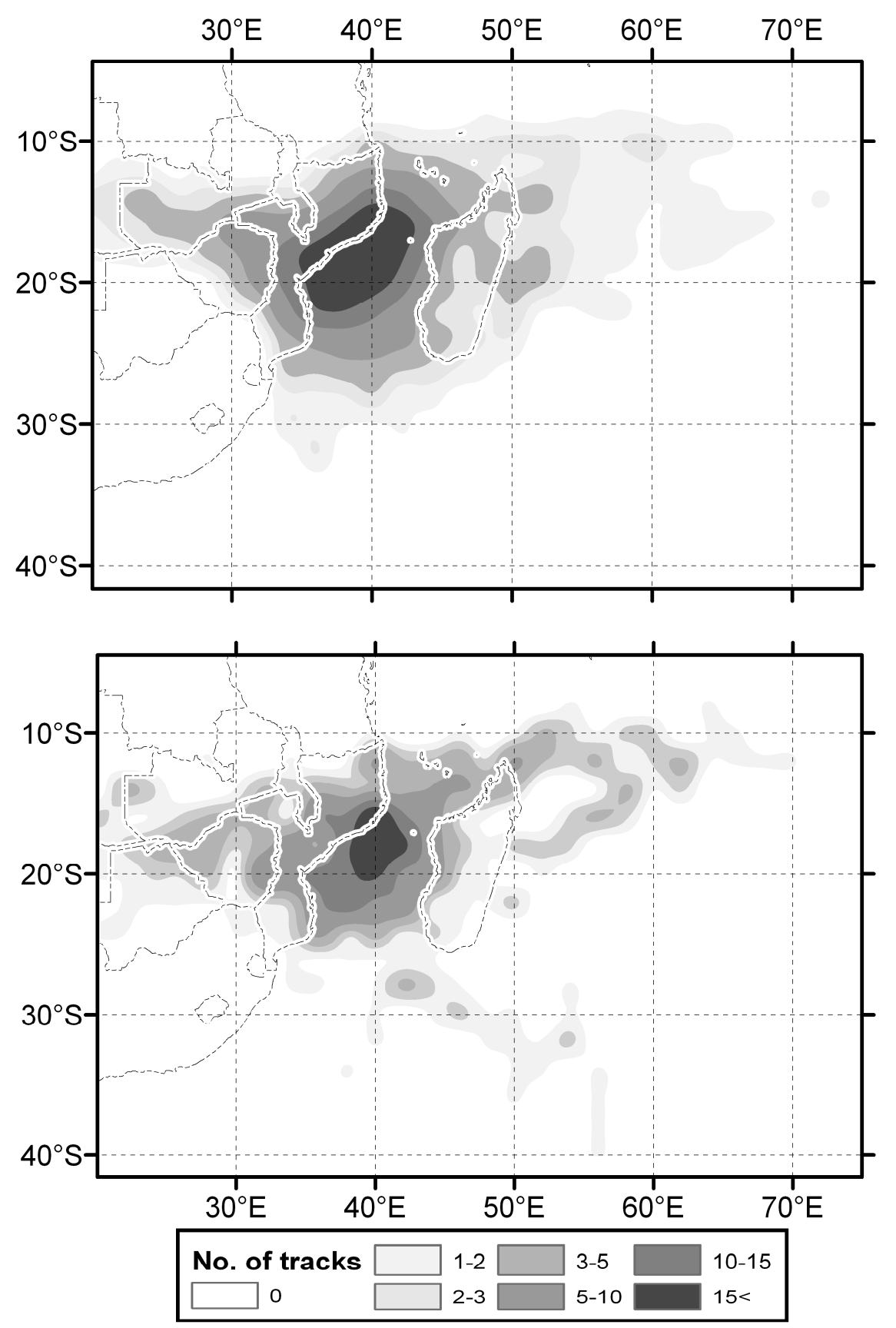

Fig. 7 Average frequency of occurrence of landfalling wam core closed lows per grid point (shaded), during January to March, as simulated by the CCAM ensemble average for 1961-1990 (top) and as according to NCEP Reanalysis data (bottom)

Considering all simulated warm core closed low pressure systems making landfall from the SWIO over the southern African subcontinent, the main region of origin of systems to the northeast of Madagascar, the preferred landfall area as well as 
the main west-northwestward inland track are all represented by the CCAM ensemble (Fig 7). For a further indication of the ability of the CCAM ensemble to simulate landfall of TCLVs (a subset of the larger set of warm core closed lows) in particular, as well as their propagation into the subcontinent, Fig. 8 shows the simulated and observed position of westward propagating systems along the $28^{\text {th }}$ longitude over southern Africa, after making landfall as TCLVs from the SWIO.

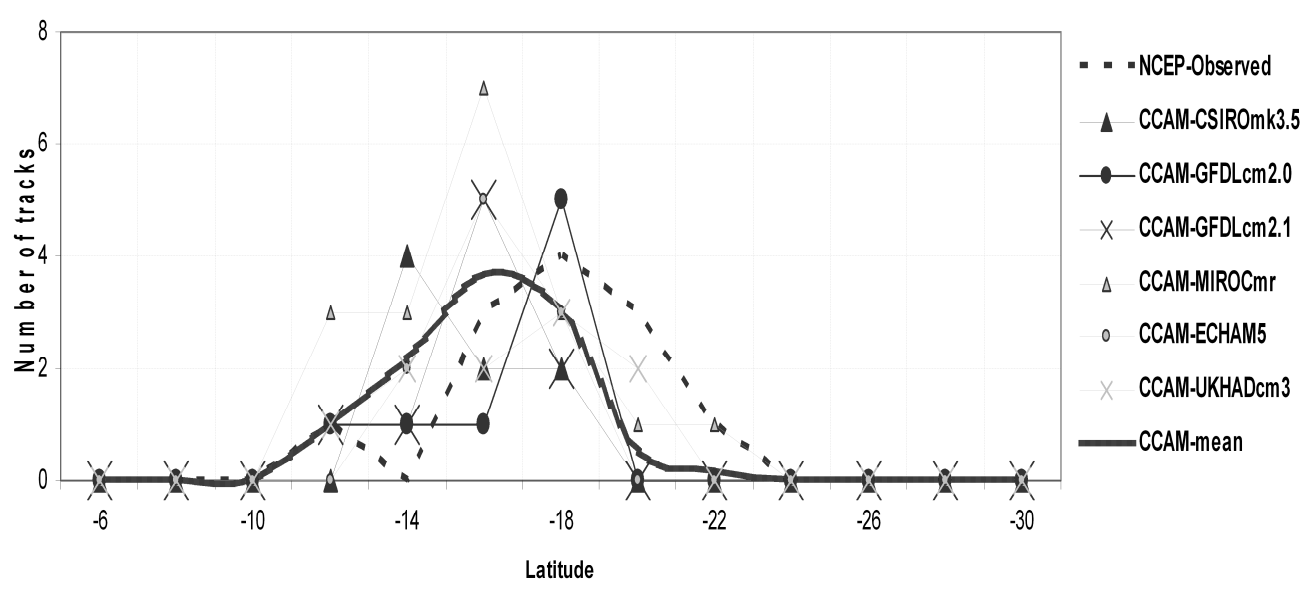

Fig. 8 Latitudinal occurrence and average frequency of occurrence during January to March, of TCLVs from the SWIO moving across $28^{\circ} \mathrm{E}$ over the period 1961-1990, as observed in NCEP reanalysis (black) and as simulated by individual CCAM ensemble members (thin lines) as well as the CCAM Ensemble mean (thick grey line)

The number of systems moving into the subcontinent as simulated by the CCAM ensemble mean represents the observations realistically, except for a systematic northward displacement of the preferred westward path. All the ensemble members show the peak latitude of landfall to the north of the observed, except for the CCAM-GFDLcm 2.0 simulation that indicates the preferred latitude to be 18 degrees $\mathrm{S}$ - as observed. The ensemble member that seems to displace the preferred tracks along this longitude furthest to the north is CCAM-CSIROmk3.5 downscaling. The north-south envelope within which westward propagation of tropical systems occurs over the interior, however, is an accurate representation of the observed. It can therefore be concluded that the CCAM ensemble is able to satisfactorily simulate the occurrence of warm-cored closed lows over the SW IO and over the southern African subcontinent after landfall. 


\section{Projected changes}

The $75^{\text {th }}, 50^{\text {th }}$ and $25^{\text {th }}$ percentiles projected change in the frequency of occurrence of TCLVs and all warm core closed low pressure systems per grid point, as represented in the simulated CCAM tracks, are shown in Fig 9. While the entire period for November-to-April was considered, the changes during the JanuaryMarch period are more pronounced than for the rest of the season (not shown) and there is no indication of a shift in the landfall season towards the early or late tropical cyclone season from the January-to-March period Changes are shown for the January-to-March season, for the period 2071-2100 relative to 1961-1990. 

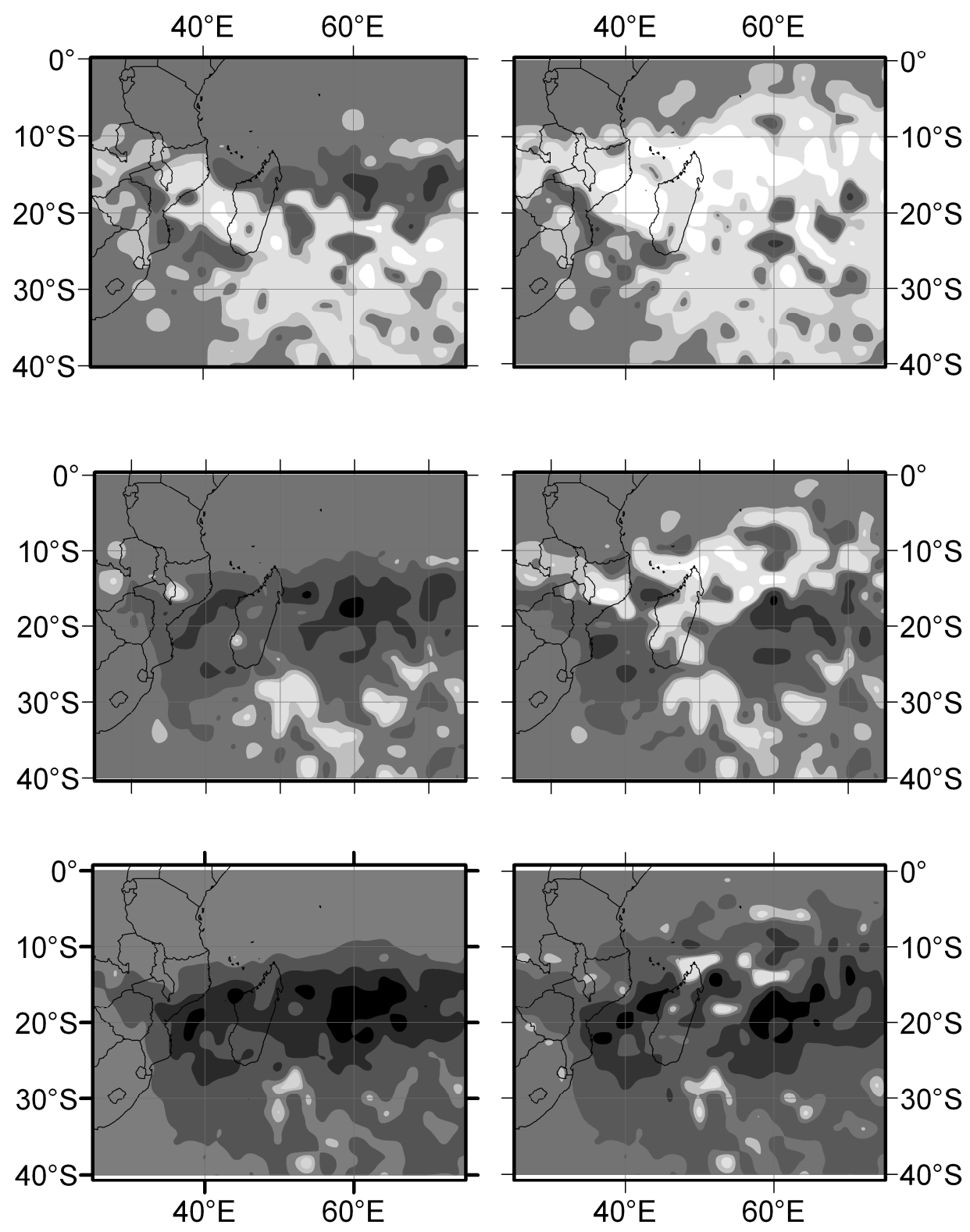

\section{Change in number of tracks}

$\square<-10 \square-1-0 \square 5-10$
$-10--5 \square 0-1$
$-5-1 \square$
-5

Fig. $975^{\text {th }}$ (top), $50^{\text {th }}$ (middle) and $25^{\text {th }}$ (bottom) percentiles of projected change in number of average January to March occurrences per grid point of TCLVs (left) and warmcore low pressure systems (right) as simulated by the CCAM ensemble for the 2071-2100 period relative to 1961-1990

The median of the CCAM ensemble indicates a general decrease in the number of TCLVs over much of the region, and a decrease of all warm core closed low 
pressure systems over the southern parts of the Mozambique Channel and the southern parts of the IO in general (Fig. 9). Increases in the frequency of occurrences of warm-core closed lows are projected to occur in a zonal band over and to the north of northern Madagascar. The $25^{\text {th }}$ and $75^{\text {th }}$ percentiles of the projected changes provide some insight into the uncertainty range described by the projections. The $75^{\text {th }}$ percentile in fact is indicative of a potential increase in the frequency of closed lows not only within a zonal band over and to the north of Madagascar, but also over large parts of the SIO. TCLVs specifically are consistently projected to decrease over the southwestern parts of the SWIO. Considering only landfalling systems, a decrease is simulated to occur in the landfall of TCLVs from the SWIO, but an increase is simulated for all tropical warm-core closed lows with the preferred latitude of landfall shifting somewhat northward (Fig. 10).

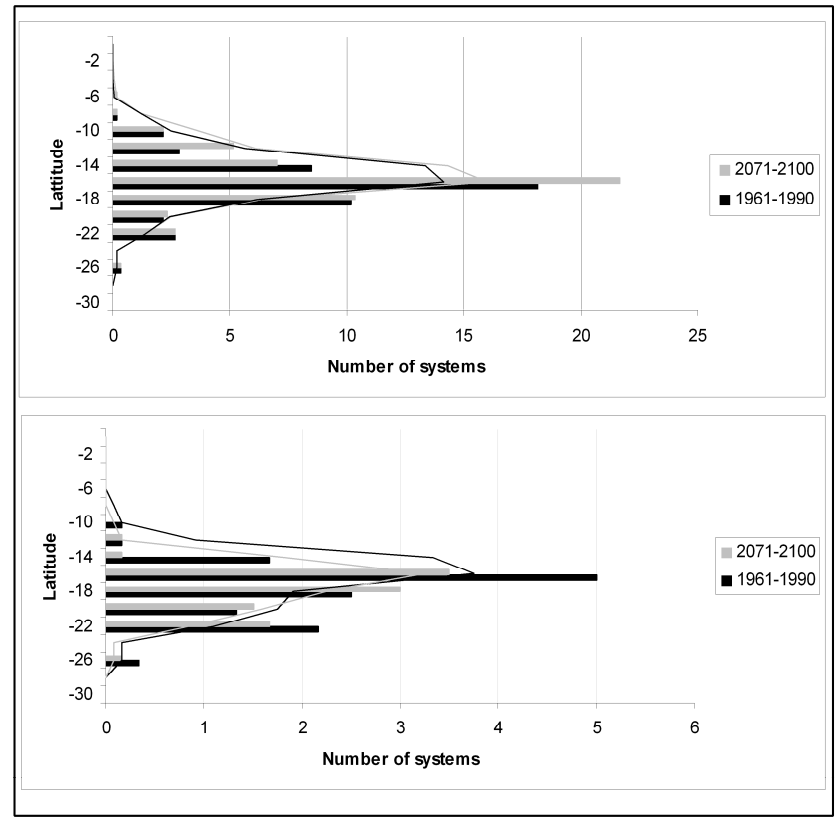

Fig. 10

Average number of warm core lows (top) and TCLVs (bottom) per $2^{\circ}$ latitude interval making landfall over southern Africa from the SW IO as simulated for the 1961-1990 (black) and 2071-2100 (grey) periods by the CCAM ensemble. Lines representing the moving averages are also indicated

Fig. 10 shows that the CCAM ensemble average indicates a general reduction in the number of landfalling TCLVs over most of the southern African coastline. 
This is also the case for all warm core lows, except over the northern parts (north of $18^{\circ} \mathrm{S}$ ), where an increase in the frequency of occurrence of such systems is projected. Consistent with the projected decrease in the landfall of all tropical systems over the southern parts of the coastline, the ensemble average projects a decrease in simulated rainfall over these areas for January to March rainfall (Fig. $11)$.

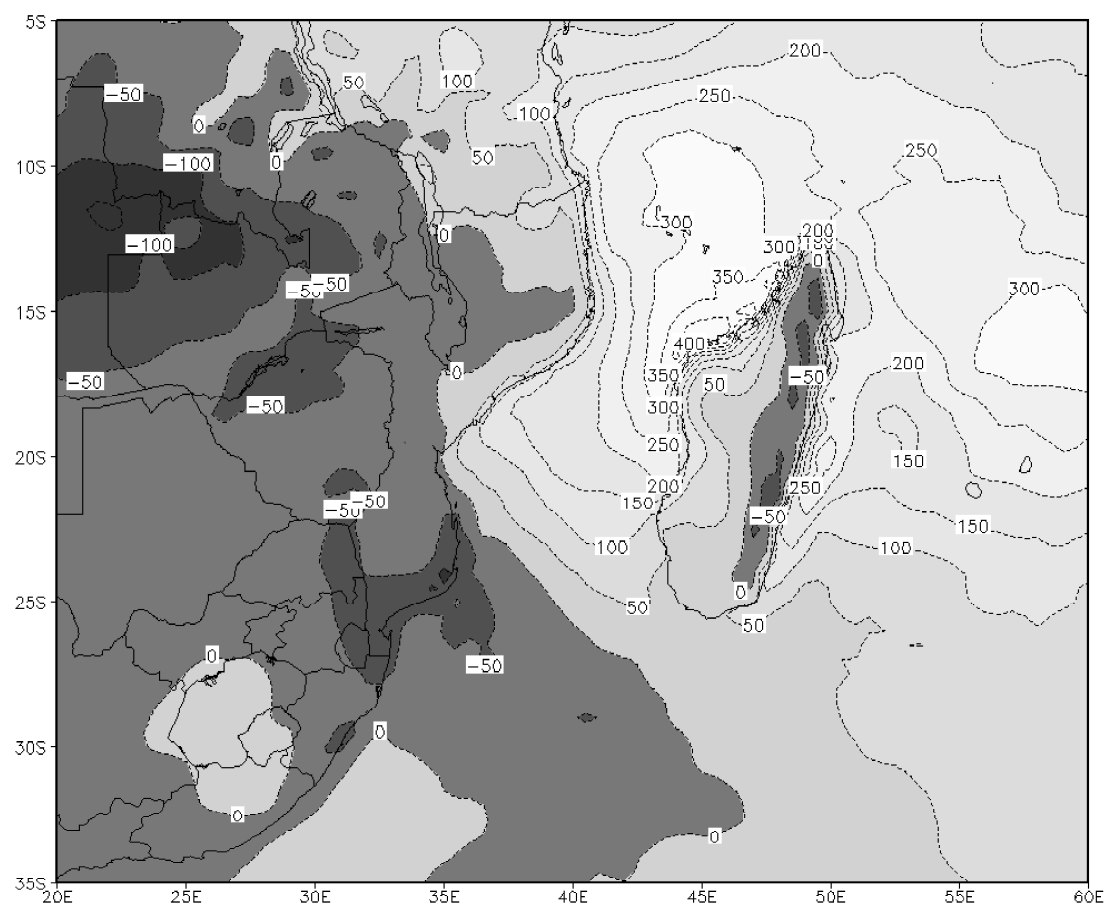

Fig. 11 CCAM ensemble average projected change in January-March rainfall between the 1961-1990 and the 2071-2100 periods

The environmental steering flow for TCVs is considered to be the weighted average of the wind vectors from $700 \mathrm{hPa}$ to $500 \mathrm{hPa}$ (Franklin et al. 1996; Jury and Pathack, 1991), whilst the large scale circulation anomalies at $700 \mathrm{hPa}$ have been associated with cyclone track characteristics (Harr and Elsberry 1991). To gain insight into how the projected change in the tracks of warm core closed lows and TCLVs in particular is brought about by changes in the regional circulation in the region, Fig. 12 shows the projected change in average January-March heights of the $700 \mathrm{hPa}$ level, for all of the CCAM ensemble members. 


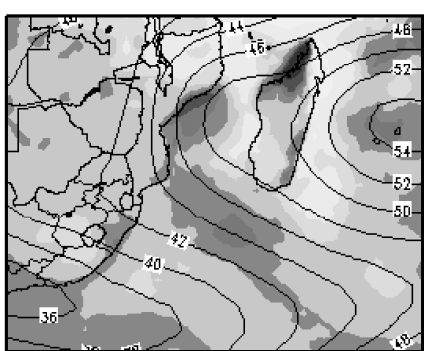

$-200-100 \quad-50 \quad-0 \quad 50 \quad 100 \quad 200$

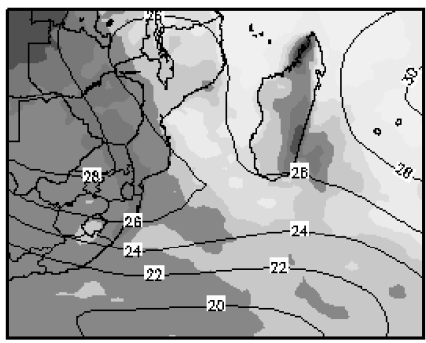

$-200-100 \quad-50 \quad-0 \quad 50 \quad 100 \quad 200$

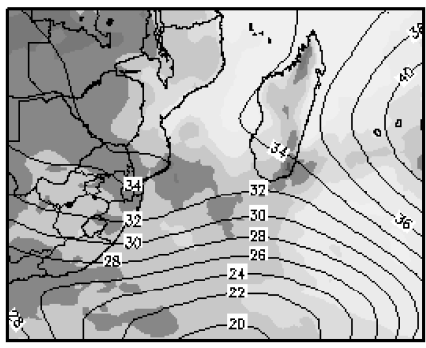

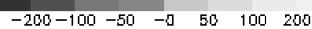

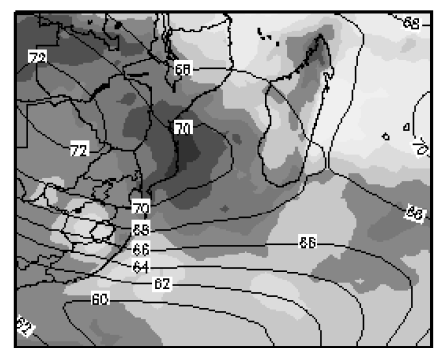

$-200-100-50 \quad-0 \quad 50 \quad 100 \quad 200$

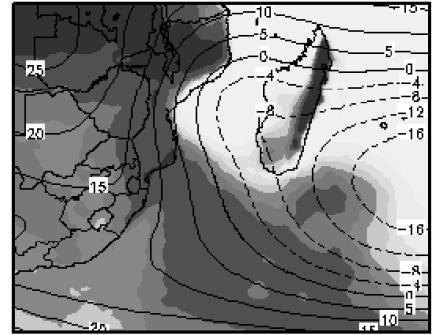

$-200-100-50 \quad-0 \quad 50 \quad 100 \quad 200$

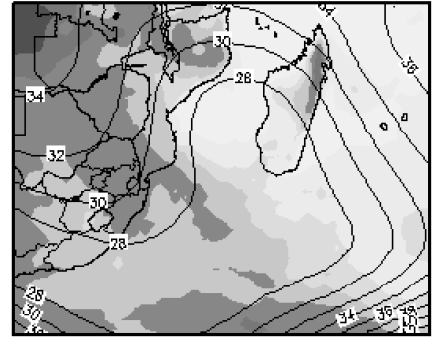

$\begin{array}{lllll}-200-100 & -50 & -0 & 50 & 100 \quad 200\end{array}$

Fig. 12 Change in average January-March rainfall (shaded) and change in average heights at $700 \mathrm{hPa}$ (contours) for 2071-2100 relative to 1961-1990 for CCAM-CSIROmk3.5 (topleft), CCAM-ECHAM5 (top right), CCAM-UKHADcm3 (middle left), CCAM-MIROC (middle right), CCAM-GFDLcm2 .0 (bottom left) and CCAM-GFDLcm2.1 (bottom right)

The general simulated increase in the height of the $700 \mathrm{hPa}$ level is due to general warming of the troposphere in the greenhouse gas warmed climate, resulting in the increase in $700 \mathrm{hPa}$ geopotential heights through the hydrostatic relationship (e.g. Engelbrecht et al. 2009). The one member that is different in this respect is CCAM-MIROC, which shows a decrease in the $700 \mathrm{hPa}$ geopotential height over a large region to the east of Madagascar, with a concurrent decrease in rainfall over the eastern parts of Madagascar. This change can be related to a large increase in the occurrence of tropical cyclones over this region, from $55^{\circ} \mathrm{E}$ eastward and south of $15^{\circ} \mathrm{S}$, by this particular ensemble member (not shown). 
Five of the six ensemble members agree broadly about the change in the average $700 \mathrm{hPa}$ height over southern African and the SWIO region. This general pattern involves a relatively larger increase in the geopotential heights over the northern parts of the subcontinent, in some cases extending eastwards over the Mozambique Channel. Relatively smaller increases are simulated further to the south over the subcontinent and the IO. Five ensemble members project this larger increases in geopotential over the subcontinent than over the adjacent SWIO, the only exception being the CCAM-CSIROmk3.5. Towards the east of Madagascar, geopotential heights are also projected to increase relatively more than the surrounding areas. All members further project an increase in the rainfall over the SWIO surrounding the northern parts of Madagascar and a decrease further south towards southern Mozambique. These findings suggest that the simulated mechanism for the northward shift in the preferred tracks of tropical systems from the SWIO may be related to a relatively larger strengthening in the subtropical ridge over the northern to eastern parts of the southern African subcontinent and towards the Mozambique Channel, causing tropical systems to move into the continent further northward around the strengthened anticyclonic circulation over these areas.

Apart from a northward displacement in the tracks of tropical systems over the SWIO and adjacent southern African subcontinent, the simulated decrease in TCLVs and also all tropical warm core closed lows over the areas to the east of South Africa and to the east of Madagascar requires further investigation. To this end, the Convective Tropical Cyclone Genesis Parameter (CTCGP) for the January-March period provides an indication of the large scale mechanisms responsible for this decrease (Fig 13). The index gives an estimation of the expected frequency of formation of tropical cyclones per $5^{\circ}$ grid point over a period of about 20 years (Caron and Jones 2008). 

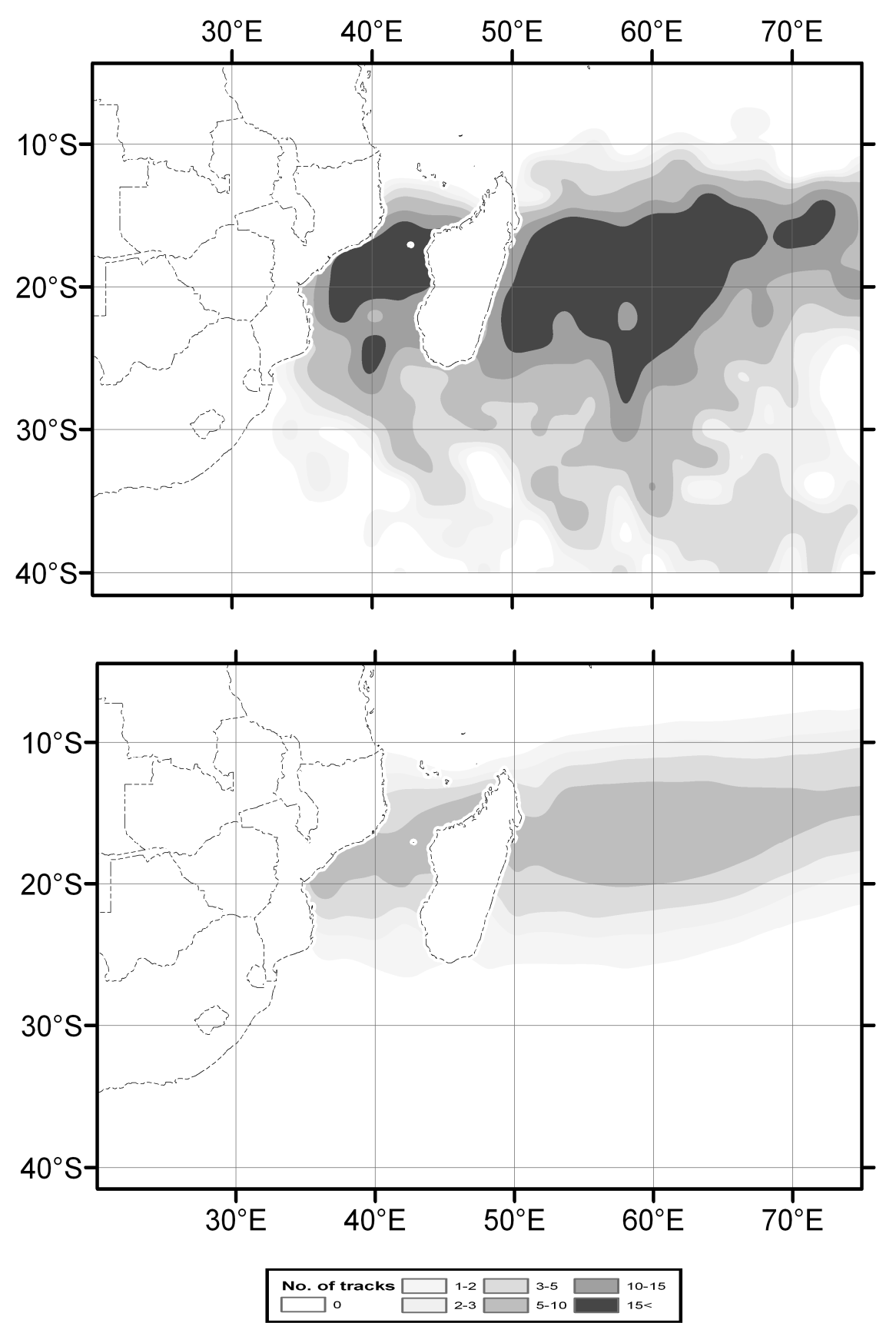

Fig. 13 Number of occurrences per grid point of TCLVs (top) as simulated by CCAM-MPI (Unit: total number of tropical cyclones passing per $2^{\circ}$ grid point over a 30 -year period) and CTCGP (Unit:approximate average twenty-yearly total number of tropical cyclones fomed per $5^{\circ}$ grid point)calculated for CCAM-MPI for the 1961-1990 period

The CTCGP estimate is consistent with the calculations of Caron and Jones (2008) based on IPCC AR4 CGCMs. Even though there should be a direct 
relationship between the number of systems formed and the number of tracks passing a point, the number of systems formed should be lower as indicated The index identifies the tropical cyclone areas and is further investigated to provide information on possible mechanisms for the change observed through tracking. The changes in this index from the 1961-1990 period to the 2071-2100 period per grid point as simulated by the ensemble members have been ranked and the $25^{\text {th }}$ percentile, median and $75^{\text {th }}$ percentile values are indicated in Fig. 14 . 

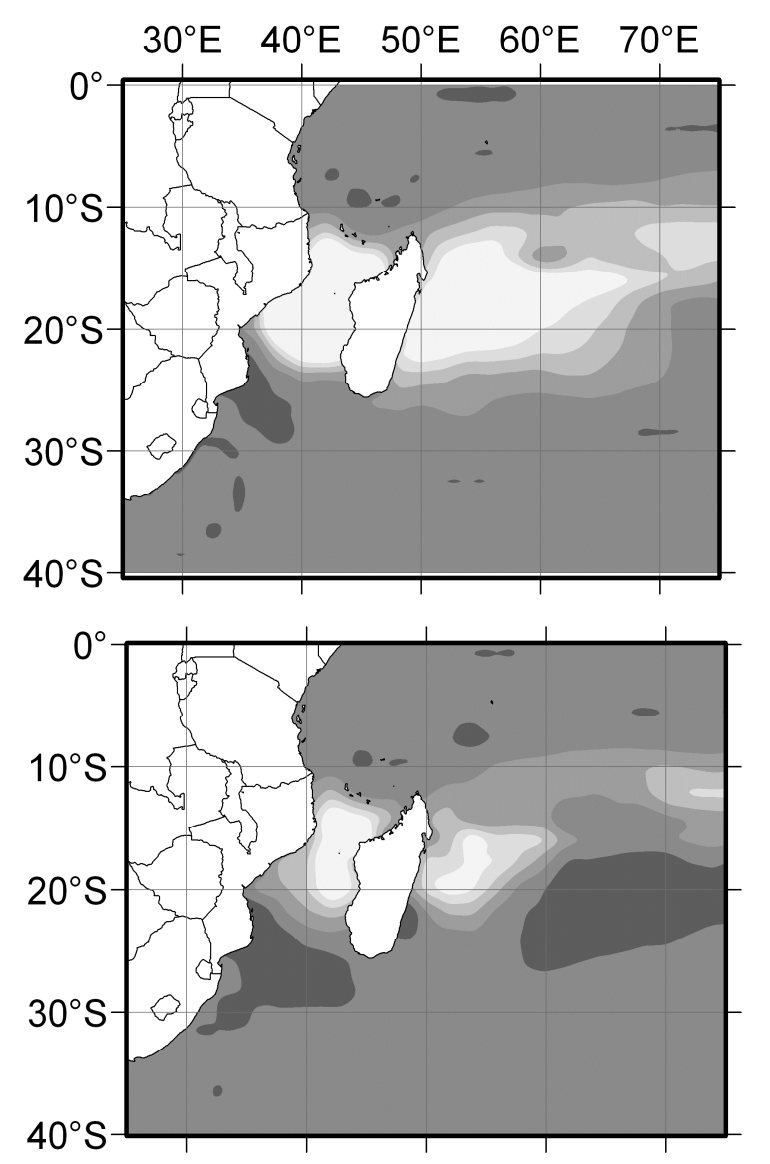

\section{Legend}

\section{Change}
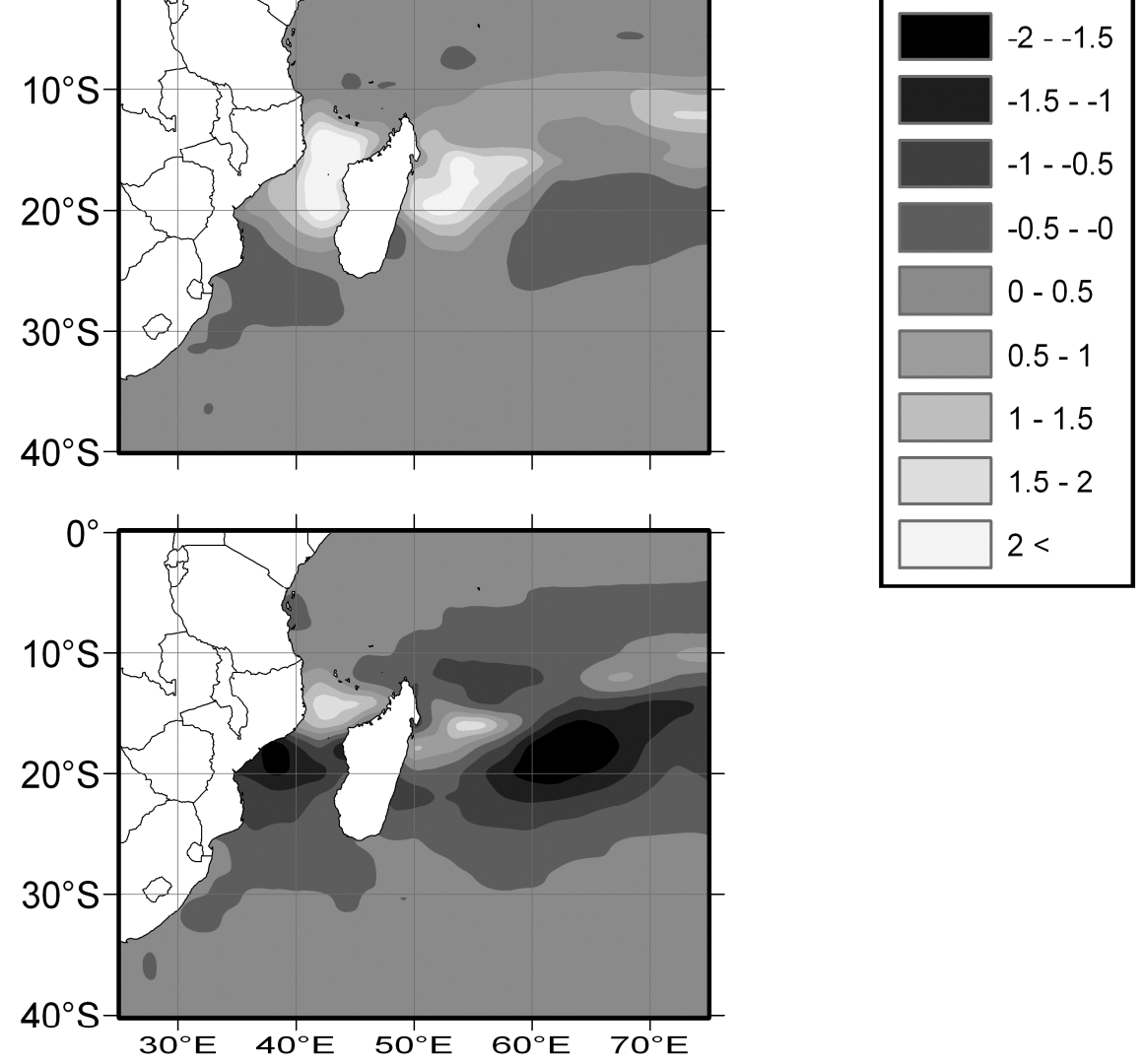

Fig. $1475^{\text {th }}$ (top), $50^{\text {th }}$ (middle) and $25^{\text {th }}$ (bottom) percentiles of the change in the Convective Tropical Cyclone Genesis Parameter (Unit: approximate average twenty-yearly total number of tropical cyclones formed per $5^{\circ}$ grid point) as calculated from the ensemble of CCAM nembers for the period 2071-2100 relative to 1961-1990

Fig. 14 shows that the findings deduced from the tracking of simulated TCLVs are supported by averages of the large scale seasonal atmospheric variables utilised in 
the CTCGP. The two areas where a decrease in both TCLVs and tropical warm core closed lows are consistently simulated (Fig. 9) by the various ensemble members, namely the southern parts of the Mozambique Channel and the southern IO between $60^{\circ}$ and $80^{\circ} \mathrm{E}, 15^{\circ}$ to $25^{\circ} \mathrm{S}$, are also indicated by the index as areas of reduced capability of the large-scale environment to support the development of tropical cyclones. The areas around northern Madagascar, where the tracking of TCLVs suggested less tropical cyclones, but an increase in the total number of all warm core closed lows, are shown to become more favourable for cyclone genesis. Uncertainty in the tracking results however over this area specifically is displayed by the relatively large positive value indicated by the $75^{\text {th }}$ percentile of simulated change.

Several factors are responsible for the decrease in conditions that favor the development of tropical cyclones over large parts of the SWIO, specifically over the southern parts of the Mozambique Channel and east of Madagascar towards the end of the $21^{\text {st }}$ century under enhanced anthropogenic forcing. Fig. 15 shows that both the dynamic and the convective (as proxy for the thermal) components of the CTCGP are implicated in the diminishing potential for tropical cyclone development over the southern parts of the Mozambique Channel, while decreases towards the east of Madagascar are more clearly associated with dynamical 

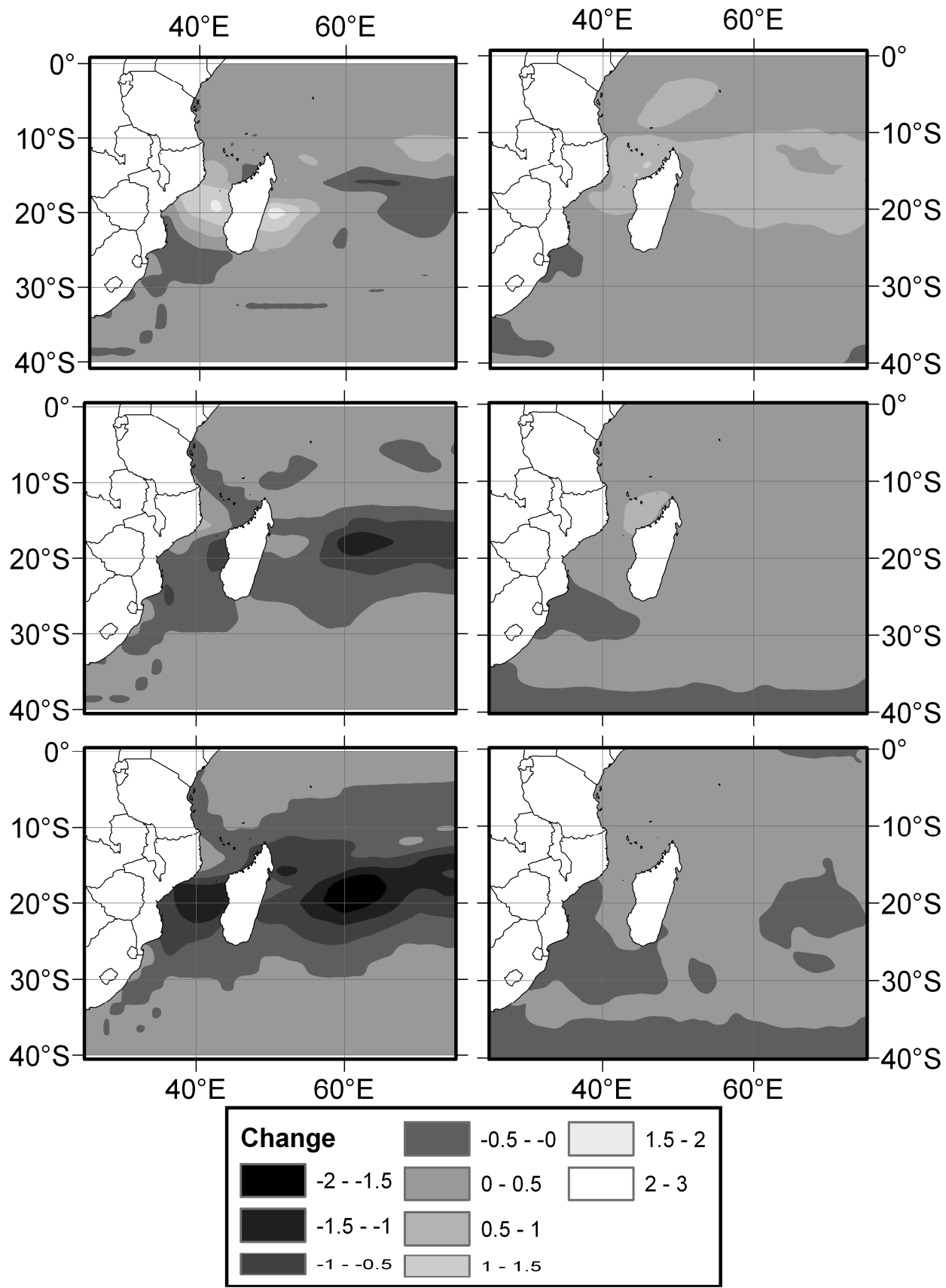

Fig. $1575^{\text {th }}$ (top), $50^{\text {th }}$ (middle) and $25^{\text {th }}$ (bottom) percentiles of the change in the dynamic (left) and convective (right) components of the Convective Tropical Cyclone Genesis Index as calculated fom the ensenble of CCAM members for the period 2071-2100 relative to 1961-1990

The convective component of the index is conducive of a decrease in tropical cyclones over especially the southern part of the Mozambique Channel, but 
indicates a potential for an increase in such systems to the north (where an increase in warm-core tropical lows is in fact projected). It is this component of the index that results in the overall indication of the potential for an increase in the number of tropical cyclones over the northern parts of the area of interest. It has been noted that rainfall over the southern African subcontinent is overestimated by CCAM (Engelbrecht et al. 2009; Engelbrecht et al. 2011). The rainfall that occurs over this region is mostly of a convective nature rather than of stratiform nature (e.g. Yang and Smith 2008). A potential overestimation of the future increase in convective rainfall in the CCAM simulations, may explain the inconsistency of the median of ensemble members projecting a decrease in the frequency of occurrence of TCLVs across the IO, whilst the median of the projections of change in the CTCGP indicate more favourable conditions for TCLV occurrence in a zonal band stretching around northern Madagascar. Indeed, most ensemble members project increases in rainfall over and to the north of the Mozambique Channel in the order of $30 \%$, with increases in the order of $20 \%$ over the remainder of the SW IO, for the period 2071-2100 relative to 1961-1990 (Engelbrecht et al., 2011). These strong increases in convective rainfall are consistent with the convective component of the index indicating an increased potential for tropical cyclone occurrence. However, the projected increase in total number of tropical warm core closed lows in this region (Fig. 9) indicates that there is indeed an increase in favourability of the environment for the development of tropical systems but with $10 \mathrm{~m}$ wind not exceeding the theoretical $13 \mathrm{~m} / \mathrm{s}$ threshold. We conclude therefore that the convective component of the index might lead to a possible overestimate of tropical cyclone genesis over the northern areas in future.

The dynamic component of the CTCGP decreases over a large part of the SW IO, especially over the area towards the south of the central Mozambique Channel and vast areas towards the east of Madagascar. Dynamic mechanisms therefore seem to be the most important factor responsible for the projected decrease in the favourability of tropical cyclone occurrence over these regions. Similarly over the North Pacific, changes in atmospheric dynamics have been found key in driving changes in that region's tropical cyclone climatology (Chan and Liu 2004). The dynamic component of the CTCGP consists of absolute vorticity at $850 \mathrm{hPa}$ and 
the wind shear between the $850 \mathrm{hPa}$ and $200 \mathrm{hPa}$ levels. Fig. 16 shows that these components both play a role in the decrease in the genesis potential over the southern parts of the Mozambique Channel and the areas towards the east of Madagascar.

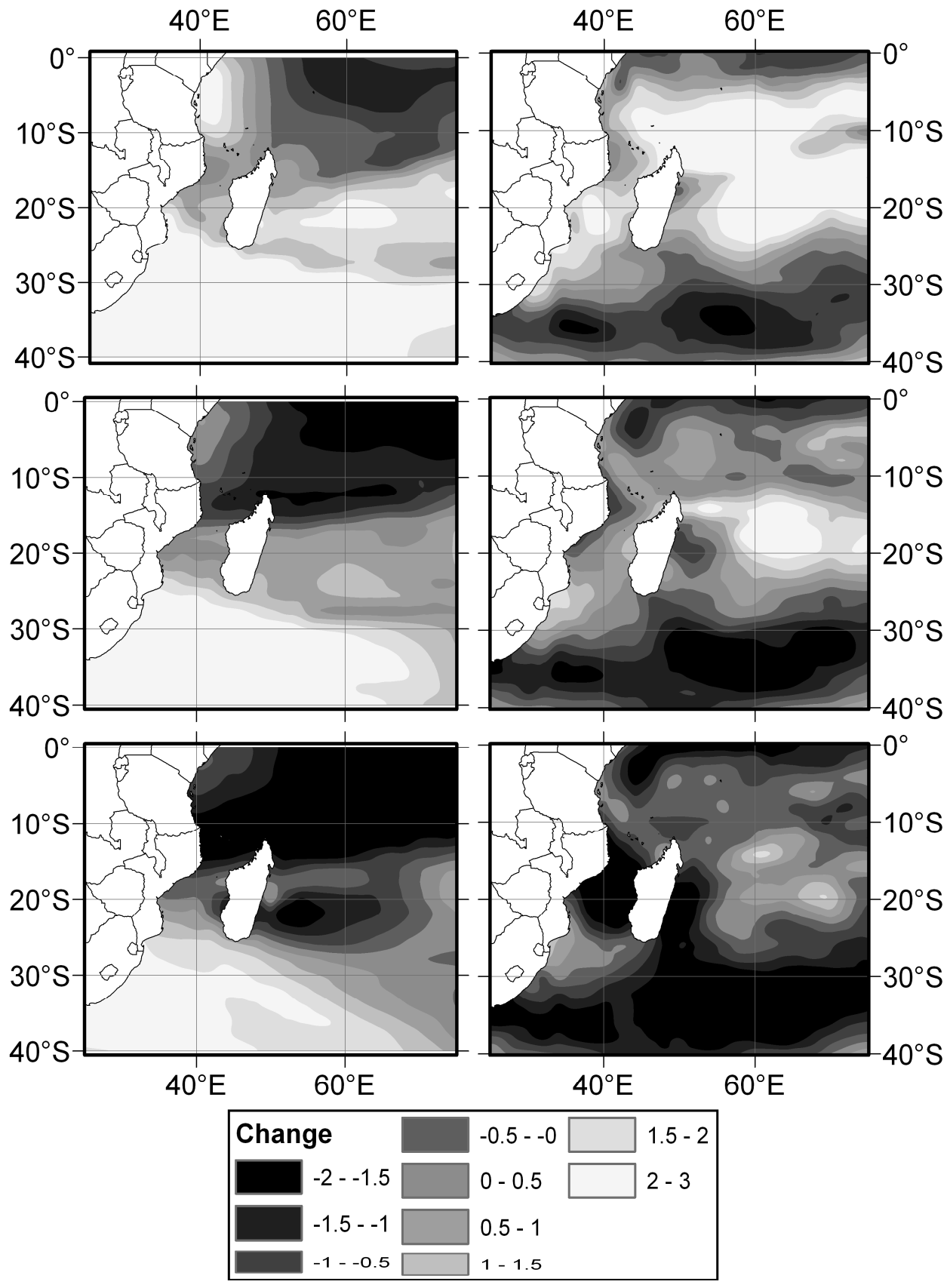

Fig. $1675^{\text {th }}$ (top), $50^{\text {th }}$ (middle) and $25^{\text {th }}$ (bottom) percentiles of the change in the average wind shear $\left(\mathrm{ms}^{-1} / 600 \mathrm{hPa}\right.$ ) between 800 and $200 \mathrm{hPa}$ (left) and the change in vorticity $\left(10^{-6} \mathrm{~s}^{-1}\right.$-right) as calculated fom the ensenble of CCAM members for the period 2071-2100 relative to 1961-1990 
South of about $20^{\circ} \mathrm{S}$, an increase in average wind shear between $850 \mathrm{hPa}$ and $200 \mathrm{hPa}$ is simulated, whilst the $850 \mathrm{hPa}$ vorticity is projected to increase (decrease in cyclonic vorticity), especially over the southern parts of the Mozambique Channel and also east of $50^{\circ} \mathrm{E}$, between $10^{\circ}$ and $20^{\circ} \mathrm{S}$. These are the two main areas showing a projected decrease in TCLVs and tropical warm core closed lows. The increase in low level vorticity adjacent to southern Africa is related to a relatively larger increase in geopotential heights relative to the surrounding areas, as described earlier.

While the thermal convective component of the CTCGP is calculated from the simulated convective rainfall, the two atmospheric components of the original TCSGP are the relative humidity at $600 \mathrm{hPa}$ and the gradient of the potential temperature between the surface and $500 \mathrm{hPa}$. The projected change in the averages of these variables is shown in Fig. 17. 


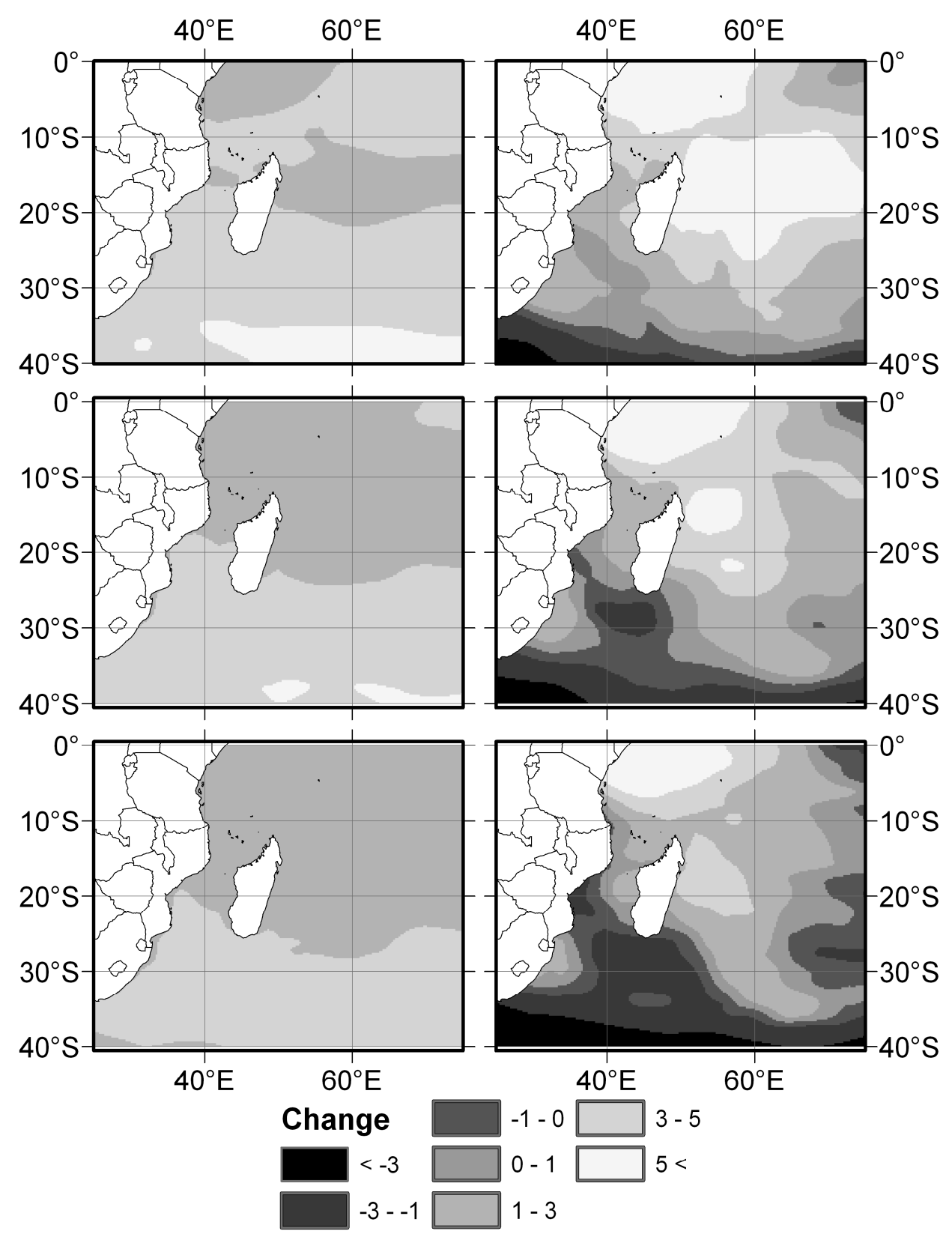

Fig. $1775^{\text {th }}$ (top), $50^{\text {th }}$ (middle) and $25^{\text {th }}$ (bottom) percentiles of the change in the gradient of potential temperature $\left(10^{-1}{ }^{\circ} \mathrm{C}\right)$ between the surface and $500 \mathrm{hPa}$ (left) and the change in Relative Humidity (\%) at $600 \mathrm{hPa}$ (right) as calculated from the ensenble of CCAM members betwen the 1961-1990 and the 2071-2100 periods

The gradient of the potential temperature between the surface and $500 \mathrm{hPa}$ is negatively related to tropical cyclone genesis (Gray 1998; Bengtsson et al. 
2007b). The projected steeper gradient in potential temperature is an indication of an increase in static stability of the atmosphere over large parts of the SWIO by the end of the $21^{\text {st }}$ century under enhanced anthropogenic forcing and may therefore be related to the overall decrease in simulated tropical cyclone frequency. Relative humidity in the midtroposphere, however, is expected to increase over most regions, counter balancing the effect of the increase in static stability on tropical cyclone genesis as used in the CTCGP, except over the areas adjacent to southern Africa over the Mozambique Channel (Fig. 17) where the majority of ensemble members indicate a decrease in this variable. These findings suggest that the future thermal properties of the atmosphere also play a role in the simulated decrease in tropical cyclone activity towards the southern parts of the Mozambique Channel and into the southeastern parts of southern Africa but to a lesser extent over the rest of the area, especially towards the north.

The projected reduction in the occurrence of tropical cyclones over parts of the SWIO, especially near southern Africa over the central and southern parts of the Mozambique Channel, can therefore be related to a change in the large scale circulation patterns as well as a change in the vertical temperature and moisture profiles of the atmosphere.

\section{Discussion}

The 6-member CCAM ensemble has captured the general spatial characteristics of the occurrence of warm core closed lows and TCLVs over the SWIO and into southern Africa realistically, as quantified by a high pattern correlation between simulated and observed fields for the 1961-1990 period. The observed preferred tracks of tropical cyclones over the SWIO, landfall positions as well as westward penetration into the subcontinent have been resolved by the simulations forced by the bias-corrected SST s and sea-ice simulations of 6 AR4 models for that period.

Projections of the CCAM ensemble based on the "business as usual" SRES scenario indicate that under enhanced anthropogenic forcing a general decrease in the frequency of tropical cyclones may occur towards the end of the $21^{\text {st }}$ century over most of the SWIO region, even though the total number of warm core closed lows over the region is projected to increase. The projected increase in the total 
number of warm core closed lows in a zonal band over and to the north of northern Madagascar is associated with increasing favourability in thermal and dynamic features of the atmosphere, while the projected decrease in TCLVs over the southern areas is related to a projected change mainly in the dynamic properties of the atmosphere (over the southern Mozambique Channel, the thermal properties are also conducive to a decrease in TCLVs). Apart from an increase in static stability in the lower to middle troposphere in agreement with earlier findings over the Northern Hemisphere ocean basins (e.g. Bengtsson et al. 2007b) and a decrease in relative humidity over the southern parts of the Mozambique Channel, the general circulation patterns are also conducive to an enhancement of vertical wind shear between the lower and upper levels of the troposphere, a phenomenon which have been related to a projected decrease in Atlantic Ocean Hurricane activity (Gamer et al. 2009). An increase in vorticity in the lower levels over especially the regions of the SWIO close to the southeastern parts of southern Africa where the strengthening of the subtropical high pressure is expected to be larger than over the surrounding areas is also indicated. Such an increase in low-level vorticity over parts of the SW IO has been linked to reduced tropical cyclone genesis over the SWIO during El-Nino years (Vitart et al. 1999).

A projected decrease in the occurrence of TCLVs is indicated in particular over the southern parts of the Mozambique Channel and the adjacent southern Africa, whilst an increase in the number of tracks of the larger family of warm core lows are projected for most of the northern regions of the southern African coast (northern Mozambique and southern Tanzania). This northward shift in the tracks of tropical systems from the SWIO over southern Africa is also the result of a relatively larger strengthening in the subtropical high pressure system over the northern to eastern parts of southern Africa relative to the areas surrounding that. Concurrently there is also a related decrease in total rainfall over much of the eastern parts of southern Africa including most of the Limpopo River Basin where the decrease in passage of tropical systems from the SWIO is projected to occur. The decrease in the simulated future occurrence and intensity of tropical systems from the SWIO moving into the Limpopo River Basin under enhanced anthropogenic forcing can have serious impacts on the water balance of this region with a largely rural population dependant on agriculture as such weather 
systems have been associated with the largest rainfall events as well as the most extensive flood events there at least since 1948.

\section{Acknowle dgements}

The authors would like to acknowledge the Water Research Commission (WRC Project No. K5/1847) in South Africa, as well as the Agricultural Research Council and the Council for Scientific and Industrial Research, South Africa, for supporting this research. All the regional climate simulations were performed on the computer clusters of the Centre for High performance Computing (CHPC) in South Africa.

We also thank the two anonymous reviewers for useful comments towards improving this manuscript.

\section{References}

Bengtsson L, Botzet M, Esch M(1995). Hurricane-type vortices in a general circulation model. Tellus 47A:175-196

Bengtsson L and Hodges KI (2006) Storm tracks and climate change J Clim 19:3518-3543

Bengtsson L, Hodges KI, Esch M (2007a) Tropical cyclones in a T159 resolution global climate model: comparison with observations and re-analyses. Tellus 59A:396-416

Bengtsson L, Hodges K I, Esch M, Keenlyside N, Kornbleuh L, Luo J-J Yamagata T (2007b) How may tropical cyclones change in a warmer climate? Tellus 59A:539561. doi: 10.1111/j.1600-0870.2007.00251.x

Bister M and Emanuel K (1998) Low fequency variability of tropical cyclone potential intensity, 2, Climatology for 1982 to 1985 . J Geophys Res, 107(D11), 4621, doi:10.1029/2001JD000780, 2002.

Blender R and Schubett M (2000) Cyclone Tracking in Different Spatial and Temporal Resolutions. Mon Weather Rev 128:377-384

Bell GD, Chelliah M (2006) Leading tropical modes associated with interannual and multidecadal fuctuations in North Atlantic huricane adivity. J Clim 19:590-612 Camargo SJ, Zebiak SE (2002) Improving the Detection and Tracking of Tropical Cyclones in Atmospheric General Circulation Models. Weather Forecast 17:11521162 
Camargo SJ, Barnston AG, Zebiak SE (2005) A statistical assessment of tropical cyclone activity in atmospheric general circulation models. Tellus 57A:589-604 Camargo SJ, Sobel AH, Barnston AG, Emanuel KA (2007a) Tropical cyclone genesis potential index in dimate models. Tellus. doi:

10.111/j.1600_0870.2007.00238.x

Camargo SJ, Emanuel KA, Sobel AH (2007b) Use of a genesis Potential index to diagnose ENSO effects on tropical cyclone genesis. J Clim 20(19):4819-4834. doi $: 10.1175 /$ JCLI4282.1

Caron LP and Jones GJ (2008) Analysing present, past and future tropical cyclone activity as inferred from an ensemble of coupled global climate models. Tellus 60 A:80-96

Christensen JH, Hewitson B, Busuioc A, Chen A, Gao X, Held I, Jones R, Koli RK, Kwon W-T, Laprise R, Rueda VM, Mearns L, Menéndez CG, Räisänen J, Rinke A, Sarr A, Whetton P (2007) Regional climate projections. Climate Change 2007: The Physical Science Basis. Contribution of Working Group I to the Fourth Assessment Report of the Intergovernmental Panel on Climate Change. In: Solomon S, Qin D, Manning M., Chen Z, Marquis M, Averyt K.B, Tignor M, Miller HL (Eds)

Cambridge University Press, Cambridge, pp 847-940

Crimp SJ and Mason SJ (1999) The Extreme Precipitation Event of 11 to 16 February 1996 over South Africa Met Atm Phys 70:29-42. doi: 10.1007/s007030050023.

Chan JCL and Liu KS (2004) Global warming and western North Pacific typhoon adivity from an observational perspectiver. J Clim 70:4590-4602

Chan JCL (2006) Comment on "changes in tropical cydone number, duration and intensity in a warming environment, Science 311: 1713

De Maria M (1996) The effect of vertical shear on tropical cyclone intensity change.

J Atm Sci 53:2076-2087

Elsner BE, Kossin JP, Jagger TH (2008) The increasing intensity of the strongest tropical cyclones. Nature 455:92-95. doi: 10.1038/nature07234.

Emanuel KA (1995) Sensitivity of tropical cyclones to surface exchange coefficients and a revised steady-state model incorporating eye dynamics. J Atm Sci 52:39693976

Emanuel KA and Nolan DS (2004) Tropical cyclone ađivity and global climate. In: Proc. of 26th Conference on Hurricanes and Tropical Meteorology, pp. 240-241, American Meteorological Society, Miami, FL.

Engelbrecht FA (2005) Simulations of climate and climate change over Southern and tropical Afica with the conformal-cubic atmospheric model. In: Schulze RE (ed) Climate Change and Water Resources in Southern Africa: Studies on Scnarios, 
Impacts, Vulnerabilities and Adaptation. Water Research Commission: Pretoria, RSA,WRC Report 1430/1/05

Engelbrecht FA, McGregor JL, Engelbrecht CJ (2009) Dynamics of the conformal cubic atmospheric model projected climate-change signal over southern Africa. Int $\mathrm{J}$ Clim 29:1013-1033

Engelbrecht FA, Landman WA, Engelbrecht CJ, Landman S, Bopape MM, Roux B, McGregor JL and Thatcher M(2011) Multi-scale dimate modeling over Southern Afica using a variable-resolution global model. Water SA 37:647-658

Engelbrecht CJ, Engelbrecht FA and Dyson LL (2012) High-resoluti on modelprojected changes in mid-tropospheric closed lows and extreme rainfall over southem Afica Int J Climatol. doi: 10.1002/joc.3420

Franklin JL, Feuer SE, Kaplan J, Aberson SD (1996) Tropical cyclone motion and surrounding flow relationships: Searching for beta gyres in omega dropsonde datasets. Mon Weather Rev 124:64 -84

Garner ST, Held IM, Knutson T, Sirutis J (2009) The Roles of Wind Shear and Thermal Stratification in Past and Projected Changes of Atlantic Tropical Cyclone Activity. J Clim 22:4723-4734. doi: http://dx.doi.org/10.1175/2009JCLI2930.1

Gibelin At and Déqué M(2003) Anthropogenic dimate change over the Mediterranean region simulated by a global variable resolution model. Clim Dyn 20:327-339. doi: 10.1007/s00382-002-0277-1

Gray WM(1988) Environmental influences on tropical cyclones. Aus Meteorol Mag 36:127-139

Gray WM(1998) The formation of tropical cydones. Met Atm Phys 76:37-69

Harr PA Elseberry RL (1991) Tropical cyclone track characteristics as a function of large-scale circulation anomalies. Mon Weather Rev 119:1448-1467

Henderson-S ellers A, Zhang H, Emanuel K, Gray W, Lnadsea C, Holland G, Lighthill J, Shieh S-L, Webster P, McGuffie K (1998) Tropical cyclones and global climate change: A post IPCC assessment. Bul Am Met Soc 79 (1):19-38

Holland GJ (1997) The maximum potential intensity of tropical cydones. J Atm sci 54:2519-254 1

Jury M(1993) A preliminary study of climatological associations and characteristics of tropical cyclones in the SW Indian Ocean. Meteorol Atmos Phys 51:101-115 Jury M and Pathack B (1991) A study of climate and weather variability over the tropical southwest Indian Ocean. Meteorol Atmos Phys 47:37048

Kalnay E, Kanamitsu M, Kistler R, Collins W, Deaven D, Derber J, Gandin L, Iredell M, Saha S, White G, Woollen J, Zhu Y, Chelliah M, Ebisuzaki W, Higgins W, Janowiak J, Mo KC, Ropelewski C, Wang J, Leetma A, Reynolds R, Jenne R, Joseph 
D (1996) The NCEP/NCAR 40-year reanalysis project. Bull Am Meteorol Soc 77:437-471

Katzfey JJ, McGregor JL, Nguyen KC, Thatcher M(2009) Dynamical downscaling techniques: impacts on regional climate change signals. In: Anderssen RS, Braddock RD and Newham LTH (ed) 18th World IMACS congress and MODSIM09 international congress on modelling and simulation. Modelling and Simulation Society of Australia and New Zealand and Intemational Association for Mathematics and Computers in Simulation, July 2009, pp 2377-2383. ISBN: 978-0-9758400-7-8. Klotzbach PJ (2006) Trends in global tropical cyclone activity over the past twenty years (1986-2005), Geophys Res Let 33:L10805. doi: 10.1029/2006GL025881

Knapp KR, Kruk MC, Levinson DH, Diamond HJ, Neumann CJ (2010) The International Best Track Archive for Climate Stewardship: Unifying tropical cydone best track data. Bull Am Meteorol Soc 91:363-376

Knutson TR, Tuleya RE, Shen W, Ginis I (2001) Impact of CO2-induced warming on hurricane intensirties as simulated in a hurricane model with ocean coupling. J Clim $14: 2458-2468$

Knutson TR, McBride JL, Chan J, Emanuel K, Holland G, Landsea C, Held I, Kossin JP, Srivastava AK, Sugi M(2010). Tropical cydones and dimate change. Nature Geoscience 3, 157-163.Kossin JP, Knapp KR, Vimont DJ, Mumane RJ, Haper BA (2007) A globally consistent reanalysis of hurricane variability. Geophys Res Lett 34: L04815

Kuleshov Y, Fawcett R, Qi L, Trewin B, Jones D, McBride J, Ramsay H(2010)

Trends in tropical cyclones in the South Indian Ocean and the South Pacific Ocean. J

Geophys Res 115: D01101. Doi: 10.1029/2009JD0 12372

Lambert SJ (1988) A cyclone climatology of the Canadian Climate Centre general circulation model. J Clim 1:109-115

Landman WA, Seth A, Camargo SJ (2005) The effect of regional dimate model domain choice on the simulation of tropical cydone-like vortices in the southwestern Indian Ocean. J Clim 18:1263-1274

Landsea CW, Harper BA, Hoarau K, Knaff JA (2006) Can we detect trends in extreme tropical cyclones? Science 313: 452-454

Liebmann B, Hendon HH, Glick JD (1994) The relationship between tropical cyclones of the Westem Pacific and Indian Oceans and the Madden-Julian Oscillation. J Meteorol Soc Jap 72(3):401-412

Malherbe J, Engelbrecht FA, Landman W A, Engelbrecht C J (2012) Tropical systems from the southwest Indian Ocean making landfall over the Limpopo River Basin, southern Africa a historical perspective. Int J Climatol. doi: 10.1002/joc.2320 
Martin LM, Chan CL (2004) Tropical cyclone intensity and vertical wind shear. Bull Am Meteorol Soc 61:1859-1876

Mavume AF, Rydberg L, Rouault M, Lutjeharms JRE (2009) Climatology and landfall of tropical cydones in the southwest Indian Ocean. W IO J Mar Sci 8 (1): 1536

McDonald RE, Bleaken DG, Cresswell DR, Pope VD, Senior CA (2005) Tropical storms: representation and diagnoses in climate models and the impacts of dimate change. Clim Dyn 25:19-36

McGregor JL(1996) Semi-Lagrangian advection on conformal-cubic grids. Mon Weather Rev 124:1311-1322

McGregor JL, Dix MR (2001) The CSIRO conformal-cubic atmospheric GCM. In: Hodnett PF (ed) IUTAM Symposium on Advances in Mathematical Modelling of Atmosphere and Ocean Dynamics. Kluwer: Dordrecht, pp 197-202

McGregor JL(2005a) Geostrophic adjustment for reversibly staggered grids. Mon Weather Rev 133:1119-1128

McGregor JL (2005b) C-CAM: Geometric aspects and dynamical formulation.

CSIRO Atmospheric Research Tech. Paper No. 70. 43 pp.

Nicholls N, Landsea C and Gill J (1998) Recent trends in Australian region tropical cyclone activity. Met Atm Phys 65:197-205

Murakami H, Wang B (2010) Future Change of North Atlantic Tropical Cyclone Tracks: Projection by a 20km-Mesh Global Atmospheric Model. J Clim 23: 2699 2721

Nguyen KC, Walsh KJE (2001) Interannual, decadal, and transient greenhouse simulation of tropical cyclone-like vortices in a regional climate model of the South Pacific. J Clim 14:3043-3054

Oouchi K, Yoshimura J, Yoshimura H, Mizuta R, Kusunoki S, Noda A(2006)

Tropical cyclone dimatology in a global-warming climate as simulated in a $20 \mathrm{~km}$ mesh global atmospheric model: frequency and wind intensity analysis. J Met Soc Jap 84(2):259-276

Ose T, Arakawa O (2009) Characteristics of the CMI3 models simulating realistic response of Tropical Western Pacific precipitation to Nino3 SST variability. J Met Soc Jap 87(4):807 - 819. doi: 10.2151/jmsj.87.807

Reason CJC, Keibel A(2004) Tropical Cydone Eline and its Unusual Penetration over the Southern African Mainland. Weather Forecast 19:789-805. doi: 10.1175/1520-0434(2004)019<0789:TCEAIU>2.0.CO 
Royer J -F, Chauvin F, Timbal P, Araspin P, Grimal D(1998) A GCM study of the impact of greenhouse gas increase on the frequency of occurrence of tropical cyclones. Clim Change 38:307-343

Sato N, Takahashi C, Seiki A, Yoneyama R, Ryuichi S (2009) An Evaluation of the Reproducibility of the Madden-Julian Oscillation in the CMIP3 Multi-Models. J Met Soc Jap 87:791-805. doi: 10.2151/jmsj.87.791

Sall SM, Sauvaot H, Gaye AT, Viltard A, de Felice P(2006) A cydogenesis index for tropical Atlantic off the Afican coasts. Atm Res 79:123-147

Singh OP, Khan TMA, Rahman Md S (2001) Probable reasons for enhanced cyclogenesis in the Bay of Bengal during July - August of ENSO years. Glob Plan Ch 29:135-147. doi: 10.1016/S0921-8181(00)00090-4

Schenkel BA, Hart RE (2012) An Examination of Tropical Cydone Position, Intensity, and Intensity Life Cycle within Atmospheric Reanalysis Datasets. J Climate 25: 3453-3475. doi:10.1175/201 1JCLI4208.1

Sugi M, Murakami H, Yoshimura J (2009) A reduction in global tropical cyclone frequency due to global warming. Sola 5:164-167. doi: 10.2151/sola2009-042 Sugi M and Noda A (2002) Influence of global waming on tropical cydone climatology: An experiment with the JMA global model. J Met Soc Jap 80:249-272 Taylor KE (2001) Summanizing multiple aspects of model performance in a single diagram. J Geophys Res 106:7183-7192

Taljaard JJ (1985) Cut-off lows in the South African region. SA Weather Bureau Technical Paper 14: 153.

Terray L, Demoray M-E, Déqué M, De Coetlogon G and Maisonnave E (2004) Simulation of late-twenty-first-century changes in wintertime atmospheric circulation over Europe due to anthropogenic causes. J Clim 17:4630-4635

Thatcher M, McGregor JL(2009) Using a Scale-Selective Filter for Dynamical Downscaling with the Conformal Cubic Atmospheric Mode. Mon Weather Rev $137: 1742-1752$

Tsutsui T (2002) Implications of anthropogenic climate change for tropical cyclone adivity: a case study with the NCAR CCM2. J Met Soc Jap 80:45-65 Van Ulden A P and Van Oldenborgh G J. 2006. Large-scale atmospheric circulation biases and changes in global climate model simulations and their importance for climate change in Central Europe. Atm Chem Phys 6: 863-881

Vimont DJ, Kossin JP (2007) The Atlantic Menidional Mode and hurricane activity. Geophys Res Lett 34:L107709. Doi: L10.1029/2006GL029683 Vit art F, Anderson L 
Stern WF(1999) Impact of Large-Scale Circulation on Tropical Storm Frequency, Intensity, and Location, Simulated by an Ensemble of GCM Integrations. J Clim 12:3237-3254. doi: 10.1175/1520-0442(1999)012<3237: IOLSCO >2.0.CO;2 Vitart F, Anderson A, Stockdale T (2003) Seasonal forecasting of tropical cyclone landfall over Mozambique. J Clim 16:3932-3945. doi: 10.1175/1520-

0442(2003)016<3932:SF OTCL $>2.0$.CO

Walsh KJE, Katzfey JJ (2000) The impact of climate change on the poleward movement of tropical cyclone-like vortices in a regional climate model. J Clim 13:1116-1132

Walsh KJE, Ryan BF (2000) Tropical cyclone intensity increase near Australia as a result of climate change. J Clim 13:3029-3036

Walsh KJE, Nguyen K-C, McGregor JL (2004) Fine resolution regional climate model simulations of the impact of climate change on tropical cyclones near Australia. Clim Dyn 22:47-56

Walsh K, Watterson I G (1997) Tropical cyclone-like vortices in a limited area model: Comparison with observed climatology. J Clim 10:2240-2259. doi:

10.1175/JCLI4074.1

Walsh KJE, Fiorino M, Landsea CW, McInnes KL (2007) Objectively detemined resolution-dependent threshold criteria for the detection of tropical cyclones in climate models and reanalysis. J Clim 20:2307-2314

Webster PJ, Holland GJ, Curry JA, Chang H-R (2005) Changes in tropical cyclone number, duration and intensity in a waming environment. Science 309:1844-1846. doi: 10.1126/science. 1116448

Yang S and Smith EA (2008) Convective-Stratiform Precipitation Variability at Seasonal Scale from $8 \mathrm{Yr}$ of TRMMObservations: Implications for Multiple Modes of Diurnal Variability. J. Clim 21:4087-4114. doi:

http://dx.doi.org/10.1175/2008JCLI2096. 1

Yoshimura J, Sugi M (2005) Tropical cyclone dimatology in ahigh-resolution AGCM - impacts of SST warming and CO2 increase. SOLA 1:133-136.

doi:10.2151/sola. 2005-035

Yu J, W ang Y (2009) Response of tropical cyclone potential intensity over the northem Indian Ocean to global warming. Geophys Res Lett 36:L03709. doi:

10.1029/2008GL036742

Yu J, W ang Y, Hamilton K (2010) Response of tropical cydone potential to a global warming scenario in the IPCC AR4 CGCMs. J Clim 23:1254-1373. doi:

10.1175/2009JCLI2843.1 
Zeng Z, Wang Y, Wu C-C (2007) Environmental dynamical control of tropical cyclone intensity - an observational study. Mon Weather Rev 135:38-59. doi: 10.1175/MW R3278.1 